\title{
A cognitive hierarchy model of behavior in the action commitment game
}

\author{
Daniel Carvalho • Luís Santos-Pinto
}

Accepted: 8 October 2013 / Published online: 7 November 2013

(C) Springer-Verlag Berlin Heidelberg 2013

\begin{abstract}
We apply the cognitive hierarchy model of Camerer et al. (Q J Econ 119(3):861-898, 2004)—where players have different levels of reasoning — to Huck et al. (Games Econ Behav 38:240-264, 2002) discrete version of Hamilton and Slutsky (Games Econ Behav 2:29-46, 1990) action commitment game-a duopoly with endogenous timing of entry. We show that, for an empirically reasonable average number of thinking steps, the model rules out Stackelberg equilibria, generates Cournot outcomes including delay, and outcomes where the first mover commits to a quantity higher than Cournot but lower than Stackelberg leader. We show that a cognitive hierarchy model with quantal responses can explain the most important features of the experimental data on the action commitment game in (2002). In order to gauge the success of the model in fitting the data, we compare it to a noisy Nash model. We find that the cognitive hierarchy model with quantal responses fits the data better than the noisy Nash model.
\end{abstract}

Keywords Action commitment game · Thinking steps · Cognitive hierarchy

JEL Classification $\quad$ C72 $\cdot \mathrm{D} 43 \cdot \mathrm{L} 13$

\footnotetext{
D. Carvalho

Banco de Portugal, Av. Almirante Reis no 71, 1150-165 Lisboa, Portugal

e-mail: dscarvalho@bportugal.pt

L. Santos-Pinto $(\varangle)$

Faculty of Business and Economics, University of Lausanne,

Internef 535, 1015 Lausanne, Switzerland

e-mail: LuisPedro.SantosPinto@unil.ch
} 


\section{Introduction}

The theoretical literature on endogenous timing tries to identify factors that might lead to the endogenous emergence of sequential or simultaneous play in oligopolistic markets. ${ }^{1}$ In Hamilton and Slutsky (1990) action commitment game, two firms must decide a quantity to be produced in one of two periods before the market clears. If a firm commits to a quantity in the first period, it will have to make its decision without knowing whether the other firm has chosen to commit early or not. If a firm commits to a quantity in the second period, then it observes the first period production of the rival (or its decision to wait).

Hamilton and Slutsky show that this game has three subgame perfect pure strategy Nash equilibria: both firms committing in the first period to the simultaneous-move Cournot-Nash equilibrium quantities, and each waiting and the other playing its Stackelberg leader quantity in the first period. They also show that only the Stackelberg equilibria survive elimination of weakly dominated strategies. ${ }^{2}$

Observed behavior in experiments on this canonical model of endogenous timing is at odds with the theory. For example, Huck et al. (2002) test experimentally the predictions of the action commitment game. They find that: (i) market outcomes are very heterogeneous, (ii) Stackelberg equilibria are rare, (iii) Cournot outcomes are modal, (iv) simultaneous-move Cournot outcomes are often played in the second period (delay), and (v) there is a high percentage of outcomes where the first mover commits to a quantity higher than Cournot but lower than Stackelberg leader.

The questions that the endogenous timing literature tries to address are particularly relevant in terms of new markets, where two or more firms will enter. The experimental evidence suggests that simultaneous-move play may be a better predictor of behavior in markets for new goods than sequential play. ${ }^{3}$ It also suggests that there may be substantial heterogeneity in behavior in these markets.

Why do we observe this gap between the theoretical predictions and the experimental evidence? One explanation might be that subjects have trouble coordinating their play in one of the two Stackelberg equilibria: if both equilibria are exactly the same then it is far from clear which of the two firms is going to assume the leading

\footnotetext{
1 The seminal papers are Saloner (1987), Hamilton and Slutsky (1990), and Robson (1990).

2 Consider the game:
}

\begin{tabular}{l|l|l|l|}
\multicolumn{1}{l}{$L$} & \multicolumn{1}{l}{$C$} & \multicolumn{1}{l}{$W$} \\
\cline { 2 - 4 }$L$ & 0,0 & 48,32 & 72,36 \\
\cline { 2 - 4 }$C$ & 32,48 & 64,64 & 64,64 \\
$W$ & 36,72 & 64,64 & 64,64 \\
\hline
\end{tabular}

In this game $L$ represents the strategy of playing the Stackelberg leader's quantity in the first period, $C$ the strategy of playing the Cournot quantity in the first period, and $W$ the strategy of waiting (and playing in the second period). This game has three pure strategy Nash equilibria $(C, C),(L, W)$ and $(W, L)$. The "Cournot equilibrium" $(C, C)$ does not survive elimination of weakly dominated strategies because strategy $C$ is weakly dominated by $W$.

3 As we have seen the prediction of Stackelberg equilibria rests on equilibrium selection arguments. Simultaneous-move Cournot-Nash equilibria typically exist, however, they do not survive the application of equilibrium refinements. 
role in the first period-see Matsumura (2001) on the instability of leader-follower relationships.

It is possible to think of explanations for some aspects of the experimental evidence. However, it is much harder to explain most of them. For example, Harsanyi and Selten (1988) risk-payoff equilibrium selection argument can explain why Cournot outcomes are more frequently played than Stackelberg outcomes since the Cournot-Nash equilibrium risk dominates (i.e. is less risky than) the Stackelberg equilibrium. ${ }^{4}$ However, risk-payoff considerations cannot explain delay, collusive or double Stackelberg leadership outcomes.

Another explanation might be inequity aversion. Santos-Pinto (2008) generalizes Hamilton and Slutsky (1990) action commitment game by assuming that players are averse to inequality in payoffs. He shows that relatively high levels of inequity aversion rule out asymmetric equilibria, and inequity aversion gives rise to a continuum of simultaneous-move equilibria which include the Cournot-Nash outcome, collusive outcomes as well as double Stackelberg leadership. However, inequity aversion is not able to explain delay. Although inequity aversion can cast some light into the experimental evidence on endogenous timing games, we believe that the discussion can be further enriched with a different focus.

Recent experiments suggest that in strategic settings without clear precedents, individuals' initial responses often deviate systematically from equilibrium. Moreover, different players seem to employ different levels of reasoning in games. Nagel (1995) was one of the first to provide evidence for this using the $p$-beauty contest, a dominance solvable game. She found that most people do not follow the Nash equilibrium prediction of behavior; rather, their degree of strategic thinking is limited to a finite number of iterations when eliminating weakly dominated strategies. Other important references on non-equilibrium models of behavior in games are Stahl and Wilson (1994), Costa-Gomes et al. (2003), and Camerer et al. (2004). In these models, a level- $k$ player computes his best response assuming that his rivals employ less thinking steps; the sole exception is that of the level zero players, who do not behave strategically and choose randomly across the strategy set. ${ }^{5}$

This paper applies Camerer et al. (2004) cognitive hierarchy model to Huck et al. (2002) discrete version of Hamilton and Slutsky (1990) action commitment game. Since this is a dynamic game and the cognitive hierarchy model is usually applied to static games we assume that: (1) a level zero player randomizes independently at each information set, and (2) players of higher levels choose best responses at information sets using backward induction and use Bayes' rule to update beliefs about their rivals' level of strategic sophistication.

\footnotetext{
4 Here "risk dominates" should be interpreted as strategic uncertainty and not as the decision theoretical notion of risk. In the game in footnote 2 the "Cournot equilibrium" $(C, C)$ risk dominates the "Stackelberg equilibrium" $(L, W)$ since the product of the deviation losses is highest for $(L, W)$ (Harsanyi and Selten 1988, Lemma 5.4.4): $(0-72)(48-72)(64-36)(64-36)=1354752>(32-64)$ $(64-64)(32-64)(64-64)=0$.

5 Ivanov et al. (2009) apply a non-equilibrium model of behavior in games to a model of endogenous timing in investment where players decide if they want to invest in a market and, if yes, when they want to carry that action out.
} 
We show that, for an empirically reasonable average number of thinking steps, the cognitive hierarchy model predicts that standard Stackelberg equilibria will not be played. We also show that the model predicts that Cournot outcomes will be frequently played, specially simultaneous play of Cournot quantities in the second period (delay). Finally, we show that the model predicts a high percentage of outcomes where the first mover commits to a quantity higher than Cournot but lower than Stackelberg leader.

The intuition behind these results is as follows. A level 1 ( $L 1$ from now on) prefers to wait since by doing that it can best respond to a level 0 ( $L 0$ from now on) who commits to period 1 . If the $L 1$ does not observe commitment by the rival in period 1 , then he chooses a Cournot quantity since this is his best response to the $L 0$ 's expected quantity. Thus, when two $L 1 \mathrm{~s}$ meet there will be delay. A level 2 ( $L 2$ from now on) faces a trade-off between committing to period 1 and waiting. If she knew the rival was an $L 1$, then she would prefer to commit to period 1 with a Stackelberg leader's quantity. If she knew that the rival was an $L 0$, then she would prefer to wait so that she could best respond to the rival when he commits to period 1 . For empirically reasonable average number of thinking steps, an $L 2$ commits to period 1 -because there is a high probability the rival is an $L 1$ - and chooses a quantity higher than Cournot but lower than Stackelberg leader-because the rival might turn out to be an $L 0$.

Next, we take the model to the data and see if it is able to explain the experimental evidence on the action commitment game in Huck et al. (2002) (HMN from now on). Since the cognitive hierarchy model typically delivers small sets of predicted behavior we introduce noise into players' behavior by assuming quantal responses (see McKelvey and Palfrey 1995; Rogers et al. 2009; Östling et al. 2011). We estimate the model using maximum likelihood and compare its predictions to the data.

We find that the cognitive hierarchy model with quantal responses is able to explain several of the most important features of the experimental data in HMN. The model predicts spikes in the Cournot quantity in periods 1 and 2. The model also predicts a high percentage of first movers who commit to a quantity higher than Cournot but lower than Stackelberg leader. The model's estimates for the percentage of players who commit to periods 1 and 2 are very close to the data. The model predicts little play of strictly dominated quantities which is also consistent with the data. The model generates heterogeneity in market outcomes (e.g., sequential play of Cournot quantities, first movers punished by second movers, double Stackelberg leadership, and collusive outcomes, among others) and predicts a high percentage of Cournot outcomes including simultaneous-move Cournot outcomes in period 2 (delay). Notwithstanding, the model's predictions for the percentages of first movers who play a particular quantity within the set of quantities that are higher than Cournot but lower than Stackelberg leader fall somewhat far from those in the data.

In order to gauge the success of the cognitive hierarchy model in fitting the data, we compare it to a noisy Nash model. This alternative model posits that players adopt the symmetric mixed strategy subgame perfect equilibrium of the action commitment game in HMN with probability $\theta_{1}$, commit to the Cournot quantity in the first period with probability $\theta_{2}$, and randomize uniformly over all actions with probability $\theta_{3}=$ $1-\theta_{1}-\theta_{2}$. We find that the cognitive hierarchy model with quantal responses fits the data better than the noisy Nash model. 
Table 1 Theoretical predictions for equilibria and fully collusive outcome

\begin{tabular}{llll}
\hline & Cournot & Stackelberg & Collusion \\
\hline Individual quantities & $q_{i}^{C}=8$ & $q^{L}=12 ; q^{F}=6$ & $\left(q_{i}^{J}=6\right)_{\text {sym }}$ \\
Total quantities & $Q^{C}=16$ & $Q^{S}=18$ & $Q^{J}=12$ \\
Profits & $\Pi_{i}^{C}=64$ & $\Pi^{L}=72 ; \Pi^{F}=36$ & $\left(\Pi_{i}^{J}=72\right)_{\text {sym }}$ \\
Consumers' surplus & $C S^{C}=128$ & $C S^{S}=162$ & $C S^{J}=72$ \\
Total welfare & $T W^{C}=256$ & $T W^{S}=270$ & $T W^{J}=216$ \\
\hline
\end{tabular}

The remainder of this paper is organized as follows. Section 2 describes the empirical evidence in HMN. Section 3 applies the cognitive hierarchy model to the action commitment game in HMN. Section 4 explains how we introduce quantal responses in the cognitive hierarchy model, reports the maximum likelihood estimates and discusses the results. Section 5 concludes the paper. The Appendix contains the payoff matrix of the action commitment game and the classification of market outcomes.

\section{Experimental evidence}

HMN use a laboratory experiment to test the action commitment model in Hamilton and Slutsky (1990). Subjects in the experiment were students of various backgrounds who were paid according to their results in the game and a participation fee to cover eventual negative profits. Subjects were told that they would act as a firm which, together with another firm, serves one market, and that in each round both were to choose the period of production and the quantity. Subjects were informed that in each round pairs of participants would be randomly matched and were not informed of who their rival was. After each round the subjects got individual feedback about what happened in their market. HMN assume a linear inverse demand function $p=30-Q$, as $Q=q_{1}+q_{2} \leq 30$ in their setting, and a cost function $C_{i}\left(q_{i}\right)=6 q_{i}$, with $i=1,2$.

Table 1, taken from Huck et al. (2001), summarizes the quantities, profits, consumer surplus and total welfare for the Cournot and Stackelberg equilibria and for the fully collusive market outcome. ${ }^{6}$

Subjects were handed a payoff matrix with discrete quantity values and the respective payoffs their choices would yield considering the quantities that their randomly matched rival might play and the rival's profit. The experiment was done with two payoff matrices, one large and one small. The large payoff matrix had quantities ranging from the integers 3 to 15 and the small payoff matrix had only 6,8 and 12 as possible choices. The play lasted 30 rounds and the subjects were informed, at the end of each round, of the quantity and time of entry their rival had chosen and the respective payoffs.

As HMN we focus on the results of the game with the large payoff matrix (see Appendix 1). In that game the quantities 6, 7, 8, and 9 are weakly dominated by the

\footnotetext{
${ }^{6}$ In this earlier paper, an experiment was performed with the same design except that the timing of the decisions was previously stipulated, either for sequential and simultaneous move. The purpose was to study Stackelberg and Cournot frameworks when subjects were matched randomly or in fixed pairs.
} 
Table 2 Observed quantities per period of play

\begin{tabular}{lccccc}
\hline & \multicolumn{2}{l}{ First 5 rounds } & & \multicolumn{2}{l}{ Entire set } \\
\cline { 2 - 3 } \cline { 6 - 6 } & Period 1 & Period 2 & & Period 1 & Period 2 \\
\hline 3 & 0.0 & 0.7 & & 0.1 & 0.3 \\
4 & 0.0 & 0.7 & & 0.1 & 0.2 \\
5 & 2.0 & 0.0 & & 0.3 & 0.2 \\
6 & 2.7 & 7.3 & & 3.9 & 2.6 \\
7 & 2.7 & 5.3 & & 6.6 & 6.9 \\
8 & 12.0 & 12.7 & & 16.0 & 14.0 \\
9 & 4.7 & 8.0 & & 5.3 & 6.3 \\
10 & 13.3 & 4.7 & & 15.6 & 4.5 \\
11 & 8.0 & 3.3 & & 6.0 & 1.9 \\
12 & 8.0 & 0.7 & & 5.2 & 1.3 \\
13 & 0.7 & 0.0 & & 0.8 & 0.2 \\
14 & 0.7 & 0.0 & & 0.4 & 0.1 \\
15 & 1.3 & 0.7 & & 0.7 & 0.3 \\
Total & 56.0 & 44.0 & 61.0 & 39.0 \\
\hline
\end{tabular}

strategy "enter the market in the second period." The quantities 3, 4, 5, 13, 14, and 15 are strictly dominated. This game has three Stackelberg equilibria in undominated strategies: two asymmetric Stackelberg equilibria in pure strategies, where one player commits to quantity 12 in period 1 and the other player waits and chooses quantity 6 , and a symmetric mixed equilibrium in which players commit to quantity 10 in period 1 with probability $2 / 5$ and with probability $3 / 5$ they wait. Furthermore, there is one pure strategy equilibrium in weakly dominated strategies, namely the Cournot equilibrium in which both players commit to quantity 8 in period 1 , and there is also a variety of mixed strategy equilibria in weakly dominated strategies. ${ }^{7}$ As Hamilton and Slutsky (1990) require equilibria not to be in weakly dominated strategies, we focus on symmetric mixed equilibrium in which players commit to quantity 10 in period 1 with probability $2 / 5$ and with probability $3 / 5$ they wait.

Table 2 displays the percentage of choices made broken down by quantity and period of play for the first five rounds and for the entire set. There are three points worth stressing from inspection of Table 2. The first is the existence of three spikes in the strategy space indicating a nonrandom structure in the reasoning of players. In period 1 there is a spike in quantity 8 and another one in quantity 10. In period 2 there is a spike in quantity 8 . The second is that more players commit to period 1 than to period 2 . The third is that the quantities chosen are highly concentrated in the subset $\{6,7,8,9,10,11,12\}$, that is, very few players choose strictly dominated quantities. ${ }^{8}$

\footnotetext{
7 In Hamilton and Slutsky (1990), the linearity of the demand and cost functions combined with the continuous action space guarantee that there are no equilibria where players mix a first period choice with the strategy "wait." With a discrete strategy space there exist various mixed strategy equilibria.

${ }^{8}$ Behavior becomes more cooperative as the number of rounds of play increases. By splitting the sample into two parts, the first encompassing the first fifteen rounds and the second the remaining rounds, we observe that: quantities 6 and 7 were chosen less often in the first part of the sample than in the second part; quantities 9 and 11 were chosen more often in the first part and less often in the second. Throughout,
} 
Table 3 Observed market outcomes

\begin{tabular}{lcc}
\hline Market outcomes (\% cases) & First 5 rounds & Entire set \\
\hline Cournot (8 or 9): & & \\
1st period & 2.7 & 4.5 \\
Sequential & 10.7 & 14.8 \\
2nd period & 6.7 & 4.5 \\
Stackelberg: & 4.0 & \\
$\quad$ Leader 12, follower 6 & 9.4 & 0.9 \\
Leader 11 or 10, follower 7 & & 6.5 \\
First mover punished or rewarded: & 6.7 & \\
Stackelberg leader punished & 0.0 & 0.2 \\
Stackelberg leader rewarded & 1.3 & 0.9 \\
Cournot (8 or 9) punished & 0.0 & 0.0 \\
Cournot (8 or 9) rewarded & 12.0 & 12.6 \\
Stackelberg and Cournot in 1st & & \\
period & & \\
Double Stackelberg leadership & 10.7 & \\
Collusion: & & 6.3 \\
Collusion successful & 4.0 & 10.6 \\
Collusion failed & 5.3 & 4.3 \\
Collusion exploited & 4.0 & 16.0 \\
Other & 22.7 & \\
\hline & &
\end{tabular}

Table 3 organizes results into market outcomes and displays the percentage of each in terms of the total. Following HMN, we count 6 and 7 as collusive quantities, 8 and 9 as Cournot quantities, and 10, 11 and 12 as Stackelberg leader's quantities.

We will briefly go through the meaning of some of the market outcomes in Table 3. The outcome "Cournot sequential" means that the first and second movers both choose a Cournot quantity (8 or 9). The outcome "Stackelberg leader punished" means that the first mover chooses a Stackelberg leader's quantity $(12,11$ or 10) and the second mover chooses a quantity greater than his best response to the first mover. The outcome "Stackelberg and Cournot in 1st period" means that one player chooses a Stackelberg leader's quantity while the other chooses a Cournot quantity. The outcome "double Stackelberg leadership" means that both players play a Stackelberg leader's quantity in period 1. The outcome "collusion successful" means that both players play a collusive quantity in either period. The outcome " collusion failed" means that both players move in period 1 , one player chooses a collusive quantity and the other player plays either Stackelberg or Cournot. The outcome "collusion exploited" means that the first mover chooses a collusive quantity and the second a quantity greater than 7 . Finally,

Footnote 8 continued

quantities 8, 10 and 12 remain approximately constant in both subsets as well as the strictly dominated quantities. 
the market outcome " others" refers to those situations that do not fit into any of the previous cases. ${ }^{9}$

\section{A cognitive hierarchy in the action commitment game}

Camerer et al. (2004) propose a cognitive hierarchy theory of behavior in games where different players employ different levels of reasoning. $L 0$ players do not think strategically at all; they randomize equally across all strategies. Players of level $k \geq 1$ anticipate the decisions of lower-level players and best respond to the mixture of their decisions using normalized frequencies. ${ }^{10}$

Formally, players of level $k \geq 1$ know the true proportions of lower-level players $f(0), f(1), \ldots, f(k-1)$. Since these proportions do not add to one, they normalize them by dividing by their sum. That is, players with $k \geq 1$ levels of reasoning have the following beliefs about players with $h$ levels of reasoning:

$$
g^{L k}(L h)=\left\{\begin{array}{ll}
f(h) / \sum_{l=0}^{k-1} f(l), & \forall h<k \\
0, & \forall h \geq k
\end{array} .\right.
$$

Camerer et al. (2004) discuss the properties that the appropriate distribution of levels should possess: it should be discrete because the thinking steps are integers; it should reflect the fact that, as thinking steps increase, so do the computations that the players carry out. Working memory constraints should make it likely that, the higher is $k$, the fewer are the players doing one further reasoning level. In other words $f(k) / f(k-1)$ is decreasing in $k$. Moreover, the authors assume that the ratio is proportional to $1 / k$ and that the distribution is the Poisson $f(k \mid \tau)=\tau^{k} e^{-\tau} / k$ !, with $k=0,1,2, \ldots$ and $\tau>0$. The advantage of this assumption is that it is reasonable and uses only one degree of freedom.

To apply the cognitive hierarchy model to the action commitment game in HMN we follow the spirit of McKelvey and Palfrey (1998) by assuming that 0-step thinkers randomize independently at each information set and higher-level types choose best responses at information sets using backward induction.

In the action commitment game in HMN a player chooses an action from the set $\{3,4, \ldots, 15\} \cup\{W\}$, where $W$ represents the action to delay. Therefore, we assume that in period 1 the $L 0$ randomizes with a discrete uniform distribution with support on $\{3,4, \ldots, 15\} \cup\{W\}$. If that is the case, then the $L 0$ plays each quantity in period 1 as well as $W$ with probability $1 / 14$, i.e.,

$$
\operatorname{Pr}_{1}^{L 0}(q)=\operatorname{Pr}_{1}^{L 0}(W)=\frac{1}{14},
$$

\footnotetext{
9 See Appendix 2 for a complete description of the quantities and periods of play that characterize each market outcome.

10 Thus, players of level $k \geq 1$ are assumed to not realize that some players might be thinking at least as 'hard' as they are about the game. This could be due to overconfidence: players believe that their rivals have less insight regarding the game they are playing. It could also be due to the limited capacity that people have to continuously eliminate dominated strategies. However, players of level $k \geq 1$ are assumed to make an accurate guess about the relative proportions of players using fewer steps than they do.
} 
for all $q \in\{3, \ldots, 15\}$. If the $L 0$ chooses $W$ in period 1 , then the $L 0$ will play each quantity in period 2 with probability $1 / 13$, i.e.,

$$
\operatorname{Pr}_{2}^{L 0}(q)=\frac{1}{13}
$$

Additionally, the best response function of a level- $k$ player, with $k \geq 1$, to quantity $q^{L r}$ chosen by his rival is given by

$$
B R^{L k}\left(q^{L r}\right)=\arg \max _{q^{L k} \in\{3, \ldots, 15\}}\left[P\left(q^{L k}+q^{L r}\right)-c\right] q^{L k} .
$$

The next step is to determine the optimal strategy of an $L 1$. An $L 1$ thinks that the population is composed only of $L 0$ s. The $L 1$ also knows that an $L 0$ will play a random quantity and will do it in period 1 with probability $13 / 14$ and in period 2 with probability $1 / 14$. We solve backwards. If the $L 1$ commits to period 2 two things can happen: the rival commits to period 1 or the rival commits to period 2 . Hence, the perceived expected profit of an $L 1$ who commits to period 2 is

$$
E\left(\pi_{2}^{L 1}\right)=\left[1-\operatorname{Pr}^{L 1}\left(W^{L 0}\right)\right] E\left(\pi_{2}^{L 1} \mid \bar{W}^{L 0}\right)+\operatorname{Pr}^{L 1}\left(W^{L 0}\right) E\left(\pi_{2}^{L 1} \mid W^{L 0}\right),
$$

where $\operatorname{Pr}^{L 1}\left(W^{L 0}\right)$ is the probability the $L 1$ assigns to the $L 0$ committing to period 2, $E\left(\pi_{2}^{L 1} \mid \bar{W}^{L 0}\right)$ is the perceived expected profit of the $L 1$ when the $L 1$ commits to period 2 and the rival commits to period 1 , and $E\left(\pi_{2}^{L 1} \mid W^{L 0}\right)$ is the perceived expected profit of the $L 1$ when the $L 1$ commits to period 2 and the rival also commits to period 2. Since

$$
\operatorname{Pr}^{L 1}\left(W^{L 0}\right)=g^{L 1}(L 0)=\operatorname{Pr}_{1}^{L 0}(W)=\frac{1}{14},
$$

we have

$$
E\left(\pi_{2}^{L 1}\right)=\frac{13}{14} E\left(\pi_{2}^{L 1} \mid \bar{W}^{L 0}\right)+\frac{1}{14} E\left(\pi_{2}^{L 1} \mid W^{L 0}\right) .
$$

If the $L 1$ commits to period 2 and the rival commits to period 1 , then the $L 1$ will be able to best respond to the quantity commitment of the rival and so

$$
E\left(\pi_{2}^{L 1} \mid \bar{W}^{L 0}\right)=\sum_{q^{L 0} \in\{3, \ldots, 15\}} \frac{1}{13} \pi^{L 1}\left(B R^{L 1}\left(q^{L 0}\right), q^{L 0}\right) .
$$

If the $L 1$ commits to period 2 and the rival also commits to period 2, then the $L 1$ 's perceived expected profit of committing to $q^{L 1}$ in period 2 is

$$
E\left[\pi_{2}^{L 1}\left(q^{L 1}\right) \mid W^{L 0}\right]=\sum_{q^{L 0} \in\{3, \ldots, 15\}} \frac{1}{13} \pi^{L 1}\left(q^{L 1}, q^{L 0}\right) .
$$


The optimal choice of the $L 1$ is the best reply to the expected output of the $L 0$ since the payoff function is linear in the opponent's strategy (demand is linear). Hence, the $L 1$ chooses $B R^{L 1}\left(\bar{q}^{L 0}\right)$ where $\bar{q}^{L 0}$ denotes the expected output of an $L 0$ and

$$
\begin{aligned}
E\left(\pi_{2}^{L 1} \mid W^{L 0}\right) & =E\left[\pi_{2}^{L 1}\left(B R^{L 1}\left(\bar{q}^{L 0}\right)\right) \mid W^{L 0}\right] \\
& =\sum_{q^{L 0} \in\{3, \ldots, 15\}} \frac{1}{13} \pi^{L 1}\left(B R^{L 1}\left(\bar{q}^{L 0}\right), q^{L 0}\right) .
\end{aligned}
$$

Substituting (2) and (4) into (1) we obtain

$$
\begin{aligned}
E\left(\pi_{2}^{L 1}\right)= & \frac{13}{14} \sum_{q^{L 0} \in\{3, \ldots, 15\}} \frac{1}{13} \pi^{L 1}\left(B R^{L 1}\left(q^{L 0}\right), q^{L 0}\right) \\
& +\frac{1}{14} \sum_{q^{L 0} \in\{3, \ldots, 15\}} \frac{1}{13} \pi^{L 1}\left(B R^{L 1}\left(\bar{q}^{L 0}\right), q^{L 0}\right) .
\end{aligned}
$$

If, on the contrary, the $L 1$ commits to quantity $q^{L 1}$ in period 1 , then the $L 1$ will attain a perceived expected profit of

$$
E\left[\pi_{1}^{L 1}\left(q^{L 1}\right)\right]=\sum_{q^{L 0} \in\{3, \ldots, 15\}} \frac{1}{13} \pi^{L 1}\left(q^{L 1}, q^{L 0}\right) .
$$

Since the $L 0$ plays randomly, the optimal quantity commitment for the $L 1$ in period 1 is $B R^{L 1}\left(\bar{q}^{L 0}\right)$. Therefore, the perceived expected profit of an $L 1$ who commits to $B R^{L 1}\left(\bar{q}^{L 0}\right)$ in period 1 is

$$
E\left[\pi_{1}^{L 1}\left(B R^{L 1}\left(\bar{q}^{L 0}\right)\right)\right]=\sum_{q^{L 0} \in\{3, \ldots, 15\}} \frac{1}{13} \pi^{L 1}\left(B R^{L 1}\left(\bar{q}^{L 0}\right), q^{L 0}\right) .
$$

By definition of the best response function, we know that

$$
\sum_{q^{L 0} \in\{3, \ldots, 15\}} \frac{1}{13} \pi^{L 1}\left(B R^{L 1}\left(q^{L 0}\right), q^{L 0}\right)>\sum_{q^{L 0} \in\{3, \ldots, 15\}} \frac{1}{13} \pi^{L 1}\left(B R^{L 1}\left(\bar{q}^{L 0}\right), q^{L 0}\right) .
$$

From (5), (7), and (8) it follows that $E\left(\pi_{2}^{L 1}\right)>E\left[\pi_{1}^{L 1}\left(B R^{L 1}\left(\bar{q}^{L 0}\right)\right)\right]$. Hence, the $L 1$ is better off by committing to period 2 , i.e.,

$$
\operatorname{Pr}_{1}^{L 1}(W)=1 .
$$

The intuition behind this result is that since $L 0$ players do not act strategically, the $L 1$ has nothing to gain if he commits to period 1 because he cannot condition the $L 0$ 's response. Therefore, waiting is the optimal choice of an $L 1$. 
Let us now determine the optimal strategy of the $L 2$. The $L 2$ thinks that the population is composed exclusively of $L 0$ s and $L 1$ s. The $L 2$ knows that an $L 0$ will play a random quantity and will do it in period 1 with probability $13 / 14$ and in period 2 with probability $1 / 14$. The $L 2$ also knows that the $L 1$ will commit to period 2 with probability $\operatorname{Pr}_{1}^{L 1}(W) .^{11}$

We solve backwards. If the $L 2$ commits to period 2 two things can happen: the rival commits to period 1 or the rival commits to period 2 . Hence, the perceived expected profit of a $L 2$ who commits to period 2 is

$$
E\left(\pi_{2}^{L 2}\right)=\left[1-\operatorname{Pr}^{L 2}\left(W^{L r}\right)\right] E\left(\pi_{2}^{L 2} \mid \bar{W}^{L r}\right)+\operatorname{Pr}^{L 2}\left(W^{L r}\right) E\left(\pi_{2}^{L 2} \mid W^{L r}\right),
$$

where $\operatorname{Pr}^{L 2}\left(W^{L r}\right)$ is the probability the $L 2$ assigns to a rival committing to period 2, $E\left(\pi_{2}^{L 2} \mid \bar{W}^{L r}\right)$ is the perceived expected profit of the $L 2$ when the $L 2$ commits to period 2 and the rival commits to period 1, and $E\left(\pi_{2}^{L 2} \mid W^{L r}\right)$ is the perceived expected profit of the $L 2$ when the $L 2$ commits to period 2 and the rival also commits to period 2. We have

$$
\begin{aligned}
\operatorname{Pr}^{L 2}\left(W^{L r}\right) & =g^{L 2}(L 0) \operatorname{Pr}_{1}^{L 0}(W)+\left[1-g^{L 2}(L 0)\right] \operatorname{Pr}_{1}^{L 1}(W) \\
& =\frac{1}{1+\tau} \frac{1}{14}+\frac{\tau}{1+\tau} \operatorname{Pr}_{1}^{L 1}(W)
\end{aligned}
$$

If the $L 2$ commits to period 2 and the rival commits to period 1, then the $L 2$ will be able to best respond to the quantity commitment of the rival and the $L 2$ 's perceived expected profit will be

$$
\begin{aligned}
E\left(\pi_{2}^{L 2} \mid \bar{W}^{L r}\right)= & \operatorname{Pr}^{L 2}\left(L 0 \mid \bar{W}^{L r}\right) \sum_{q^{L 0} \in\{3, \ldots, 15\}} \frac{1}{13} \pi^{L 2}\left(B R^{L 2}\left(q^{L 0}\right), q^{L 0}\right) \\
& +\left[1-\operatorname{Pr}{ }^{L 2}\left(L 0 \mid \bar{W}^{L r}\right)\right] \sum_{q^{L 1} \in\{3, \ldots, 15\}}\left[\operatorname{Pr}_{1}^{L 1}\left(q^{L 1}\right)\right. \\
& \left.\times \pi^{L 2}\left(B R^{L 2}\left(q^{L 1}\right), q^{L 1}\right)\right],
\end{aligned}
$$

where $\operatorname{Pr}^{L 2}\left(L 0 \mid \bar{W}^{L 0}\right)$ is the (posterior) belief of the $L 2$ that the rival is an $L 0$ given that the rival commits to period 1. Assuming the $L 2$ uses Bayes' rule to update beliefs about a rival's type we have

$$
\begin{aligned}
\operatorname{Pr}^{L 2}\left(L 0 \mid \bar{W}^{L r}\right) & =\frac{g^{L 2}(L 0)\left[1-\operatorname{Pr}_{1}^{L 0}(W)\right]}{1-\operatorname{Pr}{ }^{L 2}\left(W^{L r}\right)}=\frac{\frac{1}{1+\tau} \frac{13}{14}}{1-\left[\frac{1}{1+\tau} \frac{1}{14}+\frac{\tau}{1+\tau} \operatorname{Pr}_{1}^{L 1}(W)\right]} \\
& =\frac{\frac{1}{1+\tau} \frac{13}{14}}{\frac{1}{1+\tau} \frac{13}{14}+\frac{\tau}{1+\tau}\left[1-\operatorname{Pr}_{1}^{L 1}(W)\right]}
\end{aligned}
$$

11 The $L 2$ also knows that $\operatorname{Pr}_{1}^{L} 1(W)=1$. In Sect. 4 we will generalize the model by allowing for the possibility that players make mistakes in the timing and quantity choices and so $\operatorname{Pr}_{1}^{L 1}(W) \in(0,1)$. Hence, to make the analysis that follows compatible with that of Sect. 4 , we will not substitute $\operatorname{Pr}_{1}^{L 1}(W)$ for 1 . 


$$
=\frac{1}{1+\frac{14}{13} \tau\left[1-\operatorname{Pr}_{1}^{L 1}(W)\right]} .
$$

If the $L 2$ commits to period 2 and the rival also commits to period 2, then the $L 2$ 's perceived expected profit of committing to quantity $q^{L 2}$ in period 2 is

$$
\begin{aligned}
E\left(\pi_{2}^{L 2}\left(q^{L 2}\right) \mid W^{L r}\right)= & \operatorname{Pr}^{L 2}\left(L 0 \mid W^{L r}\right) \sum_{q^{L 0} \in\{3, \ldots, 15\}} \frac{1}{13} \pi^{L 2}\left(q^{L 2}, q^{L 0}\right) \\
& +\left[1-\operatorname{Pr}^{L 2}\left(L 0 \mid W^{L r}\right)\right] \pi^{L 2}\left(q^{L 2}, B R^{L 1}\left(\bar{q}^{L 0}\right)\right),
\end{aligned}
$$

where $\operatorname{Pr}^{L 2}\left(L 0 \mid W^{L r}\right)$ is the (posterior) belief of the $L 2$ that the rival is an $L 0$ given that the rival committed to period 2. From Bayes' rule we have

$$
\begin{aligned}
\operatorname{Pr}^{L 2}\left(L 0 \mid W^{L r}\right) & =\frac{g^{L 2}(L 0) \operatorname{Pr}_{1}^{L 0}(W)}{\operatorname{Pr}^{L 2}\left(W^{L r}\right)} \\
& =\frac{\frac{1}{1+\tau} \frac{1}{14}}{\frac{1}{1+\tau} \frac{1}{14}+\frac{\tau}{1+\tau} \operatorname{Pr}_{1}^{L 1}(W)}=\frac{1}{1+14 \tau \operatorname{Pr}_{1}^{L 1}(W)}
\end{aligned}
$$

The optimal quantity choice of the $L 2$ when the $L 2$ and the rival both commit to period 2 , denote it by $q_{2}^{L 2}$, is the solution to

$$
\begin{aligned}
& \max _{q^{L 2} \in\{3, \ldots, 15\}} \frac{1}{1+14 \tau \operatorname{Pr}_{1}^{L 1}(W)} \sum_{q^{L 0} \in\{3, \ldots, 15\}} \frac{1}{13} \pi^{L 2}\left(q^{L 2}, q^{L 0}\right) \\
& +\frac{14 \tau \operatorname{Pr}_{1}^{L 1}(W)}{1+14 \tau \operatorname{Pr}_{1}^{L 1}(W)} \pi^{L 2}\left(q^{L 2}, B R^{L 1}\left(\bar{q}^{L 0}\right)\right) .
\end{aligned}
$$

We can thus write the $L 2$ 's perceived expected profit when the $L 2$ commits to $q_{2}^{L 2}$ in period 2 and the rival also commits to period 2 as

$$
\begin{aligned}
E\left(\pi_{2}^{L 2} \mid W^{L r}\right)= & \frac{1}{1+14 \tau \operatorname{Pr}_{1}^{L 1}(W)} \sum_{q^{L 0} \in\{3, \ldots, 15\}} \frac{1}{13} \pi^{L 2}\left(q_{2}^{L 2}, q^{L 0}\right) \\
& +\frac{14 \tau \operatorname{Pr}_{1}^{L 1}(W)}{1+14 \tau \operatorname{Pr}_{1}^{L 1}(W)} \pi^{L 2}\left(q_{2}^{L 2}, B R^{L 1}\left(\bar{q}^{L 0}\right)\right) .
\end{aligned}
$$

Therefore, the $L 2$ 's perceived expected profit of committing to period 2 is

$$
\begin{aligned}
E\left(\pi_{2}^{L 2}\right)= & \frac{1}{1+\tau} \frac{13}{14} \sum_{q^{L 0} \in\{3, \ldots, 15\}} \frac{1}{13} \pi^{L 2}\left(B R^{L 2}\left(q^{L 0}\right), q^{L 0}\right) \\
& +\frac{\tau}{1+\tau}\left[1-\operatorname{Pr}_{1}^{L 1}(W)\right] \sum_{q \in\{3, \ldots, 15\}} \operatorname{Pr}_{1}^{L 1}(q) \pi^{L 2}\left(B R^{L 2}(q), q\right)
\end{aligned}
$$




$$
\begin{aligned}
& +\frac{1}{1+\tau} \frac{1}{14} \sum_{q^{L 0} \in\{3, \ldots, 15\}} \frac{1}{13} \pi^{L 2}\left(q_{2}^{L 2}, q^{L 0}\right) \\
& +\frac{\tau}{1+\tau} \operatorname{Pr}_{1}^{L 1}(W) \pi^{L 2}\left(q_{2}^{L 2}, B R^{L 1}\left(\bar{q}^{L 0}\right)\right) .
\end{aligned}
$$

If, on the contrary, the $L 2$ commits to $q^{L 2}$ in period 1 , then the $L 2$ 's perceived expected profit is

$$
\begin{aligned}
E\left[\pi_{1}^{L 2}\left(q^{L 2}\right)\right]= & \frac{1}{1+\tau} \sum_{q^{L 0} \in\{3, \ldots, 15\}} \frac{1}{13} \pi^{L 2}\left(q^{L 2}, q^{L 0}\right) \\
& +\frac{\tau}{1+\tau}\left[1-\operatorname{Pr}_{1}^{L 1}(W)\right] \sum_{q \in\{3, \ldots, 15\}} \operatorname{Pr}_{1}^{L 1}(q) \pi^{L 2}\left(q^{L 2}, q\right) \\
& +\frac{\tau}{1+\tau} \operatorname{Pr}_{1}^{L 1}(W) \pi^{L 2}\left(q^{L 2}, B R^{L 1}\left(q^{L 2}\right)\right) .
\end{aligned}
$$

The L2's optimal commitment quantity in period 1 , denote it by $q_{1}^{L 2}$, is the solution to $\max _{q L 2} \in\{3, \ldots, 15\} E\left[\pi_{1}^{L 2}\left(q^{L 2}\right)\right]$. Hence, the $L 2$ 's perceived expected profit of committing to $q_{1}^{L 2}$ in period 1 is

$$
\begin{aligned}
E\left[\pi_{1}^{L 2}\left(q_{1}^{L 2}\right)\right]= & \frac{1}{1+\tau} \sum_{q^{L 0} \in\{3, \ldots, 15\}} \frac{1}{13} \pi^{L 2}\left(q_{1}^{L 2}, q^{L 0}\right) \\
& +\frac{\tau}{1+\tau}\left[1-\operatorname{Pr}_{1}^{L 1}(W)\right] \sum_{q \in\{3, \ldots, 15\}} \operatorname{Pr}_{1}^{L 1}(q) \pi^{L 2}\left(q_{1}^{L 2}, q\right) \\
& +\frac{\tau}{1+\tau} \operatorname{Pr}_{1}^{L 1}(W) \pi^{L 2}\left(q_{1}^{L 2}, B R^{L 1}\left(q_{1}^{L 2}\right)\right) .
\end{aligned}
$$

The $L 2$ will commit to $q_{1}^{L 2}$ in period 1 if $E\left[\pi_{1}^{L 2}\left(q_{1}^{L 2}\right)\right]>E\left(\pi_{2}^{L 2}\right)$. This inequality will be satisfied for sufficiently high values of $\tau$, i.e., when, from the standpoint of an $L 2$, there are many $L 1$ s and few $L 0$ s in the population. The intuition behind this result is as follows. The $L 2$ is faced with a trade-off. If she knew the rival was an $L 1$, then she would prefer to commit to period 1 and reap the benefits of a Stackelberg leadership position. If she knew her rival was an $L 0$, then she would prefer to commit to period 2 since by doing that she is able to best respond to an $L 0$ who commits to period 1 . However, the $L 2$ only knows the percentage of $L 0$ s and $L 1$ s and so her optimal choice will depend on $\tau$. When $\tau$ is high an $L 2$ prefers to commit to period 1 since she thinks that there are many $L 1 \mathrm{~s}$ and few $L 0 \mathrm{~s}$ in the population.

We will now show that the $L 2$ commits to period 1 for sufficiently high values of $\tau$. Setting $\operatorname{Pr}_{1}^{L 1}(W)=1$ in (16), the $L 2$ 's perceived expected profit of committing to period 2 is simplified to 


$$
\begin{aligned}
E\left(\pi_{2}^{L 2}\right)= & \frac{1}{1+\tau} \frac{13}{14} \sum_{q^{L 0} \in\{3, \ldots, 15\}} \frac{1}{13} \pi^{L 2}\left(B R^{L 2}\left(q^{L 0}\right), q^{L 0}\right) \\
& +\frac{1}{1+\tau} \frac{1}{14} \sum_{q^{L 0} \in\{3, \ldots, 15\}} \frac{1}{13} \pi^{L 2}\left(q_{2}^{L 2}, q^{L 0}\right) \\
& +\frac{\tau}{1+\tau} \pi^{L 2}\left(q_{2}^{L 2}, B R^{L 1}\left(\bar{q}^{L 0}\right)\right) .
\end{aligned}
$$

The uniform distribution assumption implies $\bar{q}^{L 0}=9$ and the payoff matrix in HMN implies that 8 is the unique best response to $\bar{q}^{L 0}=9$. Hence, $B R^{L 1}\left(\bar{q}^{L 0}\right)=8$. When the $L 2$ commits to period 2 and the rival commits to period 1 , the $L 2$ is able to best respond and the $L 2$ 's perceived expected profit is 59.615 . When the $L 2$ commits to period 2 and the rival also commits to period 2 the optimal choice of the $L 2$ is $q_{2}^{L 2}=8$ for all $\tau \geq 0$. This leads to a perceived expected profit of 56 when the rival is an $L 0$ and of 64 when the rival is an $L 1$. Therefore, the $L 2$ 's perceived expected profit of committing to period 2 is

$$
\begin{aligned}
E\left(\pi_{2}^{L 2}\right) & =\frac{1}{1+\tau} \frac{13}{14} 59.615+\frac{1}{1+\tau} \frac{1}{14} 56+\frac{\tau}{1+\tau} 64 \\
& =\frac{1}{1+\tau} 59.357+\frac{\tau}{1+\tau} 64
\end{aligned}
$$

Setting $\operatorname{Pr}_{1}^{L 1}(W)=1$ in (17), the $L 2$ 's perceived expected profit of committing to $q^{L 2}$ in period 1 is simplified to

$$
\begin{aligned}
E\left[\pi_{1}^{L 2}\left(q^{L 2}\right)\right]= & \frac{1}{1+\tau} \sum_{q^{L 0} \in\{3, \ldots, 15\}} \frac{1}{13} \pi^{L 2}\left(q^{L 2}, q^{L 0}\right) \\
& +\frac{\tau}{1+\tau} \pi^{L 2}\left(q^{L 2}, B R^{L 1}\left(q^{L 2}\right)\right) .
\end{aligned}
$$

Maximizing the right-hand side of this equality with respect to $q^{L 2} \in\{3, \ldots, 15\}$ we obtain the optimal quantity of an $L 2$ who commits to period 1:

$$
q_{1}^{L 2}(\tau)=\left\{\begin{array}{lll}
8 & \text { if } & 0 \leq \tau \leq 1 \\
10 & \text { if } & 1<\tau \leq 7 \\
12 & \text { if } & 7<\tau
\end{array}\right.
$$

Therefore, the $L 2$ 's perceived expected profit of committing to $q_{1}^{L 2}(\tau)$ in period 1 is

$$
E\left[\pi_{1}^{L 2}\left(q_{1}^{L 2}(\tau)\right)\right]=\left\{\begin{array}{lll}
\frac{1}{1+\tau} 56.000+\frac{\tau}{1+\tau} 64 & \text { if } \quad 0 \leq \tau \leq 1 \\
\frac{1}{1+\tau} 49.923+\frac{\tau}{1+\tau} 70 & \text { if } 1<\tau \leq 7 \\
\frac{1}{1+\tau} 36.000+\frac{\tau}{1+\tau} 72 & \text { if } 7<\tau
\end{array}\right.
$$

From (19) and (21) we find that $\tau \geq 1.58$ implies $E\left[\pi_{1}^{L 2}\left(q_{1}^{L 2}(\tau)\right)\right]>E\left(\pi_{2}^{L 2}\right)$. Hence, if $\tau \in[1.58,7]$ the $L 2$ commits to quantity 10 in period 1 . In contrast, if $\tau \in[0,1.58)$ 
the $L 2$ commits to period 2 and (i) if the rival commits to period 1 the $L 2$ best responds, (ii) if the rival commits to period 2 the $L 2$ commits to 8 .

So, for an empirically reasonable average number of thinking steps, i.e., $\tau \in$ $[1.58,7]$, the cognitive hierarchy model predicts that $L 2$ players will commit to 10 in period 1 . Finally, we also see that the cognitive hierarchy model predicts delay and a spike in the Cournot quantity 8 in period 2 mostly due to the behavior of $L 1 \mathrm{~s}$. However, the model is not able to predict the spike in the Cournot quantity 8 in period 1 .

In short, applying the cognitive hierarchy model to the discrete action commitment game in HMN gives rise to the following behavior predictions:

$L 0$ : In period 1 the $L 0$ chooses an action randomly from the set $\{3,4, \ldots, 15\} \cup\{W\}$ using the discrete uniform distribution. As a consequence, the $L 0$ commits to period 1 with probability $13 / 14$ and to period 2 with probability $1 / 14$. In period 2 the $L 0$ chooses a quantity randomly from the set $\{3,4, \ldots, 15\}$ using the discrete uniform distribution.

L1: Commits to period 2 and (i) if the rival commits to period 1 the $L 1$ chooses a best response, (ii) if the rival commits to period 2 the $L 1$ chooses quantity 8 (a best response to 9 , the average quantity produced by an $L 0$ ).

$L 2$ : If $\tau \in[0,1.58)$, then the $L 2$ commits to period 2 and (i) if the rival commits to period 1 the $L 2$ chooses a best response, (ii) if the rival commits to period 2 the $L 2$ commits to 8 . If $\tau \in[1.58,7]$, then the $L 2$ commits to 10 in period 1 . If $\tau>7$ then the $L 2$ commits to 12 in period 1 .

Further thinking steps are easily added to the model by following the same logic as above.

\section{Estimation}

This section explains how we introduce quantal responses in the cognitive hierarchy model, reports the maximum likelihood estimates and discusses the results.

\subsection{Cognitive hierarchy with quantal responses}

Cognitive hierarchy models typically produce a rather small set of best responses. In the action commitment game, predicted behavior alternates (for players other then the $L 0$ ) between committing to period 1 with quantity 10 or waiting and, either best responding to observed quantities in the case of sequential movement, or playing quantity 8 if no commitment has been observed.

To fit the data well, it is necessary to assume that players respond stochastically rather than always choose best responses (see El-Gamal and Grether 1995; CostaGomes et al. 2001; Rogers et al. 2009; Östling et al. 2011). One way to smooth out the predicted choices over a wider range is to assume quantal responses-see McKelvey and Palfrey $(1995,1998)$. Hence, we assume that the payoff of an action chosen by a player with level $k \geq 1$ is subject to random error and that actions that yield higher payoffs have higher probability of being played. Furthermore, we assume logit quantal responses. With this framework, the error can take place both in the quantity and the timing decisions. 
The behavior of the $L 0$ has already been described in Sect. 3 . The $L 1$ thinks that the whole population is composed of $L 0 \mathrm{~s}$ and knows the behavior of the $L 0$. When the $L 1$ decides whether to commit to period 1 or 2 he anticipates his subsequent choice in period 2 and incorporates the fact that he can make a mistake in period $2 .^{12}$

If the $L 1$ commits to period 2 and the rival commits to quantity $q^{L r}$ in period 1 , then the probability that the $L 1$ commits to quantity $q \in\{3, \ldots, 15\}$ in period 2 is

$$
\operatorname{Pr}_{2}^{L 1}\left(q \mid \bar{W}^{L r}, q^{L r}\right)=\frac{e^{\lambda \pi^{L 1}\left(q, q^{L r}\right)}}{\sum_{q^{L 1} \in\{3, \ldots, 15\}} e^{\lambda \pi^{L 1}\left(q^{L 1}, q^{L r}\right)}} .
$$

If the $L 1$ commits to period 2 and the rival also commits to period 2, then the probability that the $L 1$ commits to quantity $q \in\{3, \ldots, 15\}$ in period 2 is

$$
\operatorname{Pr}_{2}^{L 1}\left(q \mid W^{L r}\right)=\frac{e^{\lambda E\left[\pi_{2}^{L 1}(q) \mid W^{L 0}\right]}}{\sum_{q^{L 1} \in\{3, \ldots, 15\}} e^{\lambda E\left[\pi_{2}^{L 1}\left(q^{L 1}\right) \mid W^{L 0}\right]}},
$$

where $E\left[\pi_{2}^{L 1}\left(q^{L 1}\right) \mid W^{L 0}\right]$ is given by (3). Therefore, if the $L 1$ commits to period 2 , then the $L 1$ 's perceived expected profit is

$$
\begin{aligned}
E\left(\pi_{2}^{L 1}\right)= & \frac{13}{14} \frac{1}{13} \sum_{q^{L 0} \in\{3, \ldots, 15\}} \sum_{q^{L 1} \in\{3, \ldots, 15\}} \operatorname{Pr}_{2}^{L 1}\left(q^{L 1} \mid \bar{W}^{L r}, q^{L 0}\right) \pi^{L 1}\left(q^{L 1}, q^{L 0}\right) \\
& +\frac{1}{14} \frac{1}{13} \sum_{q^{L 0} \in\{3, \ldots, 15\}} \sum_{q^{L 1} \in\{3, \ldots, 15\}} \operatorname{Pr}_{2}^{L 1}\left(q^{L 1} \mid W^{L r}\right) \pi^{L 1}\left(q^{L 1}, q^{L 0}\right),
\end{aligned}
$$

where $\operatorname{Pr}_{2}^{L 1}\left(q^{L 1} \mid \bar{W}^{L r}, q^{L 0}\right)$ is given by (22) and $\operatorname{Pr}_{2}^{L 1}\left(q^{L 1} \mid W^{L r}\right)$ by (23). If the $L 1$ commits to quantity $q^{L 1}$ in period 1 , then the $L 1$ 's perceived expected profit is $E\left[\pi_{1}^{L 1}\left(q^{L 1}\right)\right]$ defined in (6). Hence, the probability that the $L 1$ commits to quantity $q \in\{3, \ldots, 15\}$ in period 1 is

$$
\operatorname{Pr}_{1}^{L 1}(q)=\frac{e^{\lambda E\left[\pi_{1}^{L 1}(q)\right]}}{e^{\lambda E\left(\pi_{2}^{L 1}\right)}+\sum_{q^{L 1} \in\{3, \ldots, 15\}} e^{\lambda E\left[\pi_{1}^{L 1}\left(q^{L 1}\right)\right]}},
$$

and the probability that the $L 1$ commits to period 2 is

$$
\operatorname{Pr}_{1}^{L 1}(W)=\frac{e^{\lambda E\left(\pi_{2}^{L 1}\right)}}{e^{\lambda E\left(\pi_{2}^{L 1}\right)}+\sum_{q^{L 1} \in\{3, \ldots, 15\}} e^{\lambda E\left[\pi_{1}^{L 1}\left(q^{L 1}\right)\right]}},
$$

where $E\left(\pi_{2}^{L 1}\right)$ is given by (24) and $E\left[\pi_{1}^{L 1}\left(q^{L 1}\right)\right]$ by (6).

\footnotetext{
${ }^{12}$ Hence, for levels $L 1$ and higher, we apply the idea of agent quantal response equilibrium (AQRE) proposed by McKelvey and Palfrey (1998) where a player's agents anticipate the choices of subsequent agents and incorporate the fact that subsequent agents can make mistakes.
} 
The quantal response probabilities (22), (23), (25), and (26) characterize the behavior of a "perturbed" $L 1$. Note that the parameter $\lambda \geq 0$ is inversely related to the level of error. When $\lambda=0$ all actions consist of error and the $L 1$ becomes an $L 0$. When $\lambda=\infty$ there is no error and the behavior of the $L 1$ is "unperturbed."

Let's now turn to the behavior of the $L 2$. The $L 2$ thinks that the population is only composed of $L 0 \mathrm{~s}$ and $L 1 \mathrm{~s}$ and knows their behavior including the fact that the $L 1$ makes mistakes. Hence, the $L 2$ knows that the $L 1$ might commit to period 1 with positive probability, even though the $L 1$ 's best "unperturbed" response is to commit to period 2 . When the $L 2$ decides whether to commit to period 1 or 2 he anticipates his subsequent choice in period 2 and incorporates the fact that he can make a mistake in period 2.

If the $L 2$ commits to period 2 and the rival commits to quantity $q^{L r}$ in period 1 , then the probability that the $L 2$ commits to quantity $q \in\{3, \ldots, 15\}$ in period 2 is

$$
\operatorname{Pr}_{2}^{L 2}\left(q \mid \bar{W}^{L r}, q^{L r}\right)=\frac{e^{\lambda \pi^{L 2}\left(q, q^{L r}\right)}}{\sum_{q^{L 2} \in\{3, \ldots, 15\}} e^{\lambda \pi^{L 2}\left(q^{L 2}, q^{L r}\right)}} .
$$

If the $L 2$ commits to period 2 and the rival also commits to period 2, then the probability that the $L 2$ commits to quantity $q \in\{3, \ldots, 15\}$ in period 2 is

$$
\operatorname{Pr}_{2}^{L 2}\left(q \mid W^{L r}\right)=\frac{e^{\lambda E\left[\pi_{2}^{L 2}(q) \mid W^{L r}\right]}}{\sum_{q^{L 2} \in\{3, \ldots, 15\}} e^{\lambda E\left[\pi_{2}^{L 2}\left(q^{L 2}\right) \mid W^{L r}\right]}},
$$

where

$$
\begin{aligned}
E\left[\pi_{2}^{L 2}\left(q^{L 2}\right) \mid W^{L r}\right]= & \frac{1}{1+14 \tau \operatorname{Pr}_{1}^{L 1}(W)} \sum_{q^{L 0} \in\{3, \ldots, 15\}} \frac{1}{13} \pi^{L 2}\left(q^{L 2}, q^{L 0}\right) \\
& +\frac{14 \tau \operatorname{Pr}_{1}^{L 1}(W)}{1+14 \tau \operatorname{Pr}_{1}^{L 1}(W)} \sum_{q^{L 1} \in\{3, \ldots, 15\}}\left[\operatorname{Pr}_{2}^{L 1}\left(q^{L 1} \mid W^{L 0}\right)\right. \\
& \left.\times \pi^{L 2}\left(q^{L 2}, q^{L 1}\right)\right],
\end{aligned}
$$

and where $\operatorname{Pr}_{2}^{L 1}\left(q^{L 1} \mid W^{L 0}\right)$ is given by (23). Therefore, if the $L 2$ commits to period 2 , then the $L 2$ 's perceived expected profit is

$$
\begin{aligned}
E\left(\pi_{2}^{L 2}\right)= & \frac{1}{1+\tau} \frac{13}{14} \frac{1}{13} \sum_{q^{L 0} \in\{3, \ldots, 15\}} \sum_{q^{L 2} \in\{3, \ldots, 15\}} \operatorname{Pr}_{2}^{L 2}\left(q^{L 2} \mid \bar{W}^{L r}, q^{L r}\right) \pi^{L 2}\left(q^{L 2}, q^{L 0}\right) \\
& +\frac{1}{1+\tau} \frac{1}{14} \frac{1}{13} \sum_{q^{L 0} \in\{3, \ldots, 15\}} \sum_{q^{L 2} \in\{3, \ldots, 15\}} \operatorname{Pr}_{2}^{L 2}\left(q^{L 2} \mid W^{L r}\right) \pi^{L 2}\left(q_{2}^{L 2}, q^{L 0}\right) \\
& +\frac{\tau}{1+\tau}\left[1-\operatorname{Pr}_{1}^{L 1}(W)\right] \sum_{q^{L 1} \in\{3, \ldots, 15\}} \sum_{q^{L 2} \in\{3, \ldots, 15\}}\left[\operatorname{Pr}_{1}^{L 1}\left(q^{L 1}\right)\right. \\
& \left.\times \operatorname{Pr}_{2}^{L 2}\left(q^{L 2} \mid \bar{W}^{L r}, q^{L r}\right) \pi^{L 2}\left(q^{L 2}, q^{L 1}\right)\right]
\end{aligned}
$$




$$
\begin{aligned}
& +\frac{\tau}{1+\tau} \operatorname{Pr}_{1}^{L 1}(W) \sum_{q^{L 1} \in\{3, \ldots, 15\}} \sum_{q^{L 2} \in\{3, \ldots, 15\}}\left[\operatorname{Pr}_{1}^{L 1}\left(q^{L 1} \mid W^{L r}\right)\right. \\
& \left.\times \operatorname{Pr}_{2}^{L 2}\left(q^{L 2} \mid W^{L r}\right) \pi^{L 2}\left(q^{L 2}, q^{L 1}\right)\right]
\end{aligned}
$$

where $\operatorname{Pr}_{2}^{L 1}\left(q^{L 1} \mid W^{L r}\right)$ is given by (23), $\operatorname{Pr}_{1}^{L 1}\left(q^{L 1}\right)$ is given by $(25), \operatorname{Pr}_{1}^{L 1}(W)$ by (26), $\operatorname{Pr}_{2}^{L 2}\left(q^{L 2} \mid \bar{W}^{L r}, q^{L r}\right)$ by (27), and $\operatorname{Pr}_{2}^{L 2}\left(q^{L 2} \mid W^{L r}\right)$ by (28). If the $L 2$ commits to quantity $q^{L 2}$ in period 1 , then the $L 2$ 's perceived expected profit is

$$
\begin{aligned}
E\left[\pi_{1}^{L 2}\left(q^{L 2}\right)\right]= & \frac{1}{1+\tau} \sum_{q^{L 0} \in\{3, \ldots, 15\}} \frac{1}{13} \pi^{L 2}\left(q^{L 2}, q^{L 0}\right) \\
& +\frac{\tau}{1+\tau}\left[1-\operatorname{Pr}_{1}^{L 1}(W)\right] \sum_{q^{L 1} \in\{3, \ldots, 15\}} \operatorname{Pr}_{1}^{L 1}\left(q^{L 1}\right) \pi^{L 2}\left(q^{L 2}, q^{L 1}\right) \\
& +\frac{\tau}{1+\tau} \operatorname{Pr}_{1}^{L 1}(W) \sum_{q^{L 1} \in\{3, \ldots, 15\}}\left[\operatorname{Pr}_{2}^{L 1}\left(q^{L 1} \mid \bar{W}^{L 2}, q^{L 2}\right)\right. \\
& \left.\times \pi^{L 2}\left(q^{L 2}, q^{L 1}\right)\right],
\end{aligned}
$$

where $\operatorname{Pr}_{2}^{L 1}\left(q^{L 1} \mid \bar{W}^{L 2}, q^{L 2}\right)$ is given by (22), $\operatorname{Pr}_{1}^{L 1}\left(q^{L 1}\right)$ by (25), and $\operatorname{Pr}_{1}^{L 1}(W)$ by (26). Hence, the probability that the $L 2$ commits to quantity $q \in\{3, \ldots, 15\}$ in period 1 is

$$
\operatorname{Pr}_{1}^{L 2}(q)=\frac{e^{\lambda E\left[\pi_{1}^{L 2}(q)\right]}}{e^{\lambda E\left(\pi_{2}^{L 2}\right)}+\sum_{q^{L 2} \in\{3, \ldots, 15\}} e^{\lambda E\left[\pi_{1}^{L 2}\left(q^{L 2}\right)\right]}},
$$

and the probability that the $L 2$ commits to period 2 is

$$
\operatorname{Pr}_{1}^{L 2}(W)=\frac{e^{\lambda E\left(\pi_{2}^{L 2}\right)}}{e^{\lambda E\left(\pi_{2}^{L 2}\right)}+\sum_{q^{L 2} \in\{3, \ldots, 15\}} e^{\lambda E\left[\pi_{1}^{L 2}\left(q^{L 2}\right)\right]}},
$$

where $E\left(\pi_{2}^{L 2}\right)$ is given by (29) and $E\left[\pi_{1}^{L 2}\left(q^{L 2}\right)\right]$ by (30).

The quantal response probabilities (27), (28), (31), and (32) characterize the behavior of a "perturbed" $L 2$. We see that, by comparison to the situation where there are no errors in players' choices, the $L 2$ has less room to condition the $L 1$ 's play since now there is a positive probability that the $L 1$ will commit to period 1 . Hence, the cognitive hierarchy model with quantal responses will make different predictions than cognitive hierarchy model in Sect. 3.

The process is similar for all higher levels of reasoning and so we stop here.

\subsection{Maximum likelihood estimation}

The estimation goes through all the pairs of decisions. By pair, we mean every possible combination of period and quantity decisions of two players playing against each other. 
This approach captures the interaction of players taking decisions that are conditioned by their rivals' decisions. The information is thus broken down into three possible cases: both players commit to period 1; both players commit to period 2; and one player commits to period 1 and the other to period $2 .{ }^{13}$

The probability that players 1 and 2, paired up against each other, with reasoning levels $k_{1}$ and $k_{2}$, play a given pair of timing and quantity choices $\left(t_{1}, q_{1}, t_{2}, q_{2}\right)$ is:

$$
\begin{aligned}
f\left(t_{1}, q_{1}, t_{2}, q_{2} \mid \tau, \lambda\right)= & \sum_{k_{1}=0}^{K} \sum_{k_{2}=0}^{K} p^{L k_{1}}\left(t_{1}, q_{1} \mid \tau, \lambda\right) f\left(k_{1} \mid \tau\right) \\
& \times p^{L k_{2}}\left(t_{2}, q_{2} \mid \tau, \lambda\right) f\left(k_{2} \mid \tau\right) .
\end{aligned}
$$

The likelihood function then goes through all possible pairs of choices

$$
L(\tau, \lambda)=\prod_{t_{1}=1}^{2} \prod_{q_{1}=3}^{15} \prod_{t_{2}=1}^{2} \prod_{q_{2}=3}^{15}\left[f\left(t_{1}, q_{1}, t_{2}, q_{2} \mid \tau, \lambda\right)\right]^{n_{\left(t_{1}, q_{1}, t_{2}, q_{2}\right)}}
$$

where $t_{i}$ and $q_{i}$ are the timing and quantity predictions for player $i$ in a given pair, $t$ is the index of timing predictions and $q$ for quantity predictions, $n_{\left(t_{1}, q_{1}, t_{2}, q_{2}\right)}$ is the number of cases that each pair is observed in the data, and $\tau$ is the parameter of the Poisson distribution. Since cognitive hierarchy models are better suited to explain initial responses (see Crawford et al. 2012) our benchmark estimation is done for the first five rounds of play. However, we also estimate the model for the entire set (30 rounds of play). The estimation method is maximum likelihood and it is done according to a standard grid search approach. ${ }^{14}$

In order to gauge the success of $\mathrm{CH}$ model in fitting the data, we compare it to an alternative model, which we call the noisy Nash model (NN). This alternative model posits that players adopt the symmetric mixed strategy subgame perfect equilibrium with probability $\theta_{1}$, commit to the Cournot quantity 8 in the first period with probability $\theta_{2}$, and randomize uniformly over all actions with probability $1-\theta_{1}-\theta_{2}$.

\subsection{Results}

We now present and discuss the results of the maximum likelihood estimations. Table 4 displays the estimates of $\tau$ and $\lambda$ for the $\mathrm{CH}$ model, the estimates of $\theta_{1}$ and $\theta_{2}$ for the

\footnotetext{
13 Crawford and Iriberri (2007) and Harless and Camerer (1995) use a similar estimation procedure.

14 The routine starts with initial values $\lambda=0$ and $\tau=0$ and generates the predictions of the model, i.e., the probability of timing and quantity decision for each type of player for all levels $k \in\{1,2, \ldots, 10\}$. After, the estimated probabilities of timing and quantity decision of levels $k \in\{1,2, \ldots, 10\}$ are aggregated with the probabilities of timing and quantity decisions of the $L 0$ to obtain the estimated probabilities of each pair of timing and quantity choices. The estimated probabilities of each pair of timing and quantity choices are evaluated in the likelihood function. The procedure is repeated several times in a grid search for both parameters $\lambda$ and $\tau$. Finally, the values of $\lambda$ and $\tau$ that yield the highest value of the likelihood function are extracted. Parallel routines in both GAUSS and MATLAB were used for checking the validity of estimates.
} 
Table 4 Maximum likelihood estimates

\begin{tabular}{rrr}
\hline & First 5 rounds & Entire set \\
\hline $\mathrm{CH}$ & & \\
$\tau$ & 1.29 & 1.69 \\
$\lambda$ & 0.62 & 0.49 \\
$\mathcal{L}$ & -400.76 & -2263.03 \\
$\mathrm{NN}$ & & 0.28 \\
$\theta_{1}$ & 0.30 & 0.12 \\
$\theta_{2}$ & 0.08 & -2445.70 \\
$\mathcal{L}$ & -422.74 & \\
\hline
\end{tabular}

NN model, and the respective likelihood values. The estimates are reported for the first five rounds of play and for the entire set.

The estimate of the average number of thinking steps in the $\mathrm{CH}$ model is 1.29 for the first five rounds of play and 1.69 for the entire set. The estimate of $\tau$ for the first five rounds of play implies that $27.5 \%$ of players are $L 0,35.5 \%$ are $L 1,22.9 \%$ are $L 2,9.8 \%$ are $L 3,3.2 \%$ are $L 4$, and the remaining $1.1 \%$ of players are $L 5$ and higher. The estimates for $\tau$ are in line with those found in Camerer et al. (2004) who show that the average estimate for $\tau$ across a wide range of games is 1.5 . Nevertheless, it should be pointed out that other estimates for $\tau$ are not uncommon in the literature. For example, the lowest estimate for $\tau$ in the seven weeks of the LUPI game in Östling et al. (2011) is 2.98, the remaining six are above 5 and the highest are over 10. In Rogers et al. (2009) there are games for which the predicted $\tau$ is also rather high. ${ }^{15}$

The estimates for $\theta_{1}$ and $\theta_{2}$ in the $\mathrm{NN}$ model are 0.30 and 0.08 , respectively, for the first five rounds of play and 0.28 and 0.12 for the entire set. In the first five rounds of play, the estimates imply that $30 \%$ of players choose the symmetric mixed strategy subgame perfect equilibrium, $8 \%$ commit to the first period to the Cournot quantity 8 , and $62 \%$ display random behavior. Comparing the likelihood values we see that the NN model generates a poorer fit of the data in the first five rounds of play and in the entire set.

We now turn towards the quality of the adjustment. Table 5 displays upper and lower bounds to the maximum likelihood value as well as log-likelihood ratios for the test of hypothesis that all players randomize uniformly over all actions ( $p$ values are in parenthesis). The upper bound is obtained by running the likelihood function with the empirical frequencies of the pairs of play. By definition, this procedure yields the maximum value attainable for the estimation. The lower bound is the maximum likelihood value of the $\mathrm{CH}$ and the $\mathrm{NN}$ models when there is only random play (it is obtained by setting $\lambda=0$ in the $\mathrm{CH}$ model or by setting $\theta_{1}=\theta_{2}=0$ in the $\mathrm{NN}$

15 Camerer et al. (2004) argue that subjects tend do employ a cost-benefit analysis concerning the amount of thinking they do in games. They present evidence that the higher the stakes of a given game, the higher will $\tau$ be: they show that subjects tend to think harder in games that yield $\$ 4$ than games that yield $\$ 1$. Since the LUPI game is based on data from an actual lotto game that existed in Sweden with a prize money of at least $€ 10,000$, it makes sense that the game's estimates should be relatively high (even though, of course, the probability of winning the prize is much smaller). In the large matrix experiment we used, subjects received the equivalent to $\$ 11.44$, on average, which, given the reward, places our model's estimates somewhere in the middle of this range. 
Table 5 Quality of adjustment

\begin{tabular}{lll}
\hline & First 5 rounds & Entire set \\
\hline Upper bound & -336.62 & -1825.90 \\
Lower bound & -519.40 & -2963.62 \\
Log-likelihood ratios & & \\
CH & $237.28(0.000)$ & $1401.18(0.000)$ \\
NN & $193.32(0.000)$ & $1035.84(0.000)$ \\
\hline
\end{tabular}

Table 6 Observed and predicted quantities per period of play

\begin{tabular}{|c|c|c|c|c|c|c|c|c|c|c|c|c|}
\hline \multirow[t]{3}{*}{ Quantity } & \multicolumn{6}{|c|}{ First 5 rounds } & \multicolumn{6}{|c|}{ Entire set } \\
\hline & \multicolumn{3}{|c|}{ Period 1} & \multicolumn{3}{|c|}{ Period 2} & \multicolumn{3}{|c|}{ Period 1} & \multicolumn{3}{|c|}{ Period 2} \\
\hline & Data & $\mathrm{CH}$ & $\mathrm{NN}$ & Data & $\mathrm{CH}$ & $\mathrm{NN}$ & Data & $\mathrm{CH}$ & $\mathrm{NN}$ & Data & $\mathrm{CH}$ & NN \\
\hline 3 & 0.0 & 2.0 & 4.4 & 0.7 & 0.3 & 0.3 & 0.1 & 1.3 & 4.3 & 0.3 & 0.2 & 0.3 \\
\hline 4 & 0.0 & 2.0 & 4.4 & 0.7 & 0.7 & 0.3 & 0.1 & 1.3 & 4.3 & 0.2 & 0.5 & 0.3 \\
\hline 5 & 2.0 & 2.0 & 4.4 & 0.0 & 1.7 & 1.9 & 0.3 & 1.7 & 4.3 & 0.2 & 1.3 & 1.8 \\
\hline 6 & 2.7 & 3.6 & 4.4 & 7.3 & 4.5 & 1.9 & 3.9 & 4.1 & 4.3 & 2.6 & 4.0 & 1.8 \\
\hline 7 & 2.7 & 6.3 & 4.4 & 5.3 & 9.0 & 4.1 & 6.6 & 8.4 & 4.3 & 6.9 & 7.7 & 3.7 \\
\hline 8 & 12.0 & 13.8 & 12.3 & 12.7 & 15.5 & 8.2 & 16.0 & 17.8 & 16.3 & 14.0 & 11.8 & 8.0 \\
\hline 9 & 4.7 & 9.8 & 4.4 & 8.0 & 7.3 & 1.1 & 5.3 & 13.6 & 4.3 & 6.3 & 6.5 & 1.0 \\
\hline 10 & 13.3 & 6.4 & 13.9 & 4.7 & 2.6 & 1.9 & 15.6 & 8.1 & 15.5 & 4.5 & 2.4 & 1.8 \\
\hline 11 & 8.0 & 2.6 & 4.4 & 3.3 & 1.0 & 1.1 & 6.0 & 2.6 & 4.3 & 1.9 & 0.7 & 1.0 \\
\hline 12 & 8.0 & 2.0 & 4.4 & 0.7 & 0.3 & 0.3 & 5.2 & 1.6 & 4.3 & 1.3 & 0.2 & 0.3 \\
\hline 13 & 0.7 & 2.0 & 4.4 & 0.0 & 0.2 & 0.3 & 0.8 & 1.3 & 4.3 & 0.2 & 0.1 & 0.3 \\
\hline 14 & 0.7 & 2.0 & 4.4 & 0.0 & 0.2 & 0.3 & 0.4 & 1.3 & 4.3 & 0.1 & 0.1 & 0.3 \\
\hline 15 & 1.3 & 2.0 & 4.4 & 0.7 & 0.2 & 0.3 & 0.7 & 1.3 & 4.3 & 0.3 & 0.1 & 0.3 \\
\hline Total & 56.0 & 56.5 & 77.2 & 44.0 & 43.5 & 22.0 & 61.0 & 64.4 & 79.1 & 39.0 & 35.6 & 20.9 \\
\hline
\end{tabular}

model). As is evident from the $\log$-likelihood $p$ values, we can reject the hypothesis that all players randomize uniformly over all actions.

Table 6 displays the percentage of choices, broken down by quantity and period of play, in the data and predicted by the $\mathrm{CH}$ and $\mathrm{NN}$ models.

We will focus our analysis of the results on the first five periods of play since the results for the entire set are very similar. The first thing we can see from Table 6 is that the $\mathrm{CH}$ model predicts spikes in quantities 8 and 9 in period 1 together with smaller spikes in the adjacent quantities 7 and 10. The $\mathrm{CH}$ model also predicts a spike in quantity 8 in period 2 together with smaller spikes in the adjacent quantities 7 and 9. The $\mathrm{CH}$ model estimates for commitment to periods 1 and 2 (56.5 and $43.5 \%$, respectively) are very close to the data (56 and $44 \%$, respectively). The $\mathrm{CH}$ model overestimates play of strictly dominated quantities by only $8.5 \%$. Nevertheless, the $\mathrm{CH}$ model underestimates the percentage of first movers who play quantities 12, 10 and 11 , and overestimates the percentage of first movers who play quantity 9 .

The NN model predicts spikes in the quantities 8 and 10 in period 1 as well as a spike in quantity 8 in period 2 . However, the $\mathrm{NN}$ model overestimates period 1 commitment by $21.2 \%$ and overestimates play of strictly dominated quantities by $23 \%$. Finally, we 
Table 7 Probabilities of action choice: first 5 rounds

\begin{tabular}{|c|c|c|c|c|c|c|c|c|c|c|c|}
\hline \multirow[t]{2}{*}{ Share } & $L 0$ & $L 1$ & $L 2$ & $L 3$ & $L 4$ & L5 & $L 6$ & $L 7$ & $L 8$ & $L 9$ & $L 10$ \\
\hline & 27.5 & 35.5 & 22.9 & 9.8 & 3.2 & 0.9 & 0.2 & 0.0 & 0.0 & 0.0 & 0.0 \\
\hline$p_{1}^{L k}(3)$ & 7.1 & 0.0 & 0.0 & 0.0 & 0.0 & 0.0 & 0.0 & 0.0 & 0.0 & 0.0 & 0.0 \\
\hline$p_{1}^{L k}(4)$ & 7.1 & 0.0 & 0.0 & 0.0 & 0.0 & 0.0 & 0.0 & 0.0 & 0.0 & 0.0 & 0.0 \\
\hline$p_{1}^{L k}(5)$ & 7.1 & 0.4 & 0.0 & 0.0 & 0.0 & 0.0 & 0.0 & 0.0 & 0.0 & 0.0 & 0.0 \\
\hline$p_{1}^{L k}(6)$ & 7.1 & 4.2 & 0.5 & 0.5 & 0.6 & 0.6 & 0.6 & 0.6 & 0.6 & 0.6 & 0.6 \\
\hline$p_{1}^{L k}(7)$ & 7.1 & 7.8 & 4.1 & 4.9 & 5.3 & 5.4 & 5.5 & 5.5 & 5.5 & 5.5 & 5.5 \\
\hline$p_{1}^{L k}(8)$ & 7.1 & 14.5 & 16.7 & 20.1 & 21.2 & 21.6 & 21.7 & 21.7 & 21.7 & 21.7 & 21.7 \\
\hline$p_{1}^{L k}(9)$ & 7.1 & 4.2 & 15.2 & 19.9 & 20.6 & 20.8 & 20.8 & 20.8 & 20.8 & 20.8 & 20.8 \\
\hline$p_{1}^{L k}(10)$ & 7.1 & 0.4 & 9.7 & 14.9 & 14.9 & 14.9 & 14.9 & 14.9 & 14.9 & 14.9 & 14.9 \\
\hline$p_{1}^{L k}(11)$ & 7.1 & 0.0 & 1.2 & 2.2 & 2.1 & 2.1 & 2.1 & 2.1 & 2.1 & 2.1 & 2.1 \\
\hline$p_{1}^{L k}(12)$ & 7.1 & 0.0 & 0.1 & 0.2 & 0.2 & 0.2 & 0.2 & 0.2 & 0.2 & 0.2 & 0.2 \\
\hline$p_{1}^{L k}(13)$ & 7.1 & 0.0 & 0.0 & 0.0 & 0.0 & 0.0 & 0.0 & 0.0 & 0.0 & 0.0 & 0.0 \\
\hline$p_{1}^{L k}(14)$ & 7.1 & 0.0 & 0.0 & 0.0 & 0.0 & 0.0 & 0.0 & 0.0 & 0.0 & 0.0 & 0.0 \\
\hline$p_{1}^{L k}(15)$ & 7.1 & 0.0 & 0.0 & 0.0 & 0.0 & 0.0 & 0.0 & 0.0 & 0.0 & 0.0 & 0.0 \\
\hline$p_{1}^{L k}(W)$ & 7.1 & 68.5 & 52.4 & 37.4 & 35.0 & 34.4 & 34.3 & 34.2 & 34.2 & 34.2 & 34.2 \\
\hline$p_{2}^{L k}(3)$ & 0.5 & 0.0 & 0.0 & 0.0 & 0.0 & 0.0 & 0.0 & 0.0 & 0.0 & 0.0 & 0.0 \\
\hline$p_{2}^{L k}(4)$ & 0.5 & 0.0 & 0.0 & 0.0 & 0.0 & 0.0 & 0.0 & 0.0 & 0.0 & 0.0 & 0.0 \\
\hline$p_{2}^{L k}(5)$ & 0.5 & 0.8 & 0.1 & 0.0 & 0.0 & 0.0 & 0.0 & 0.0 & 0.0 & 0.0 & 0.0 \\
\hline$p_{2}^{L k}(6)$ & 0.5 & 9.2 & 1.4 & 1.2 & 1.2 & 1.2 & 1.2 & 1.2 & 1.2 & 1.2 & 1.2 \\
\hline$p_{2}^{L k}(7)$ & 0.5 & 17.0 & 9.7 & 7.5 & 7.1 & 7.0 & 7.0 & 7.0 & 7.0 & 7.0 & 7.0 \\
\hline$p_{2}^{L k}(8)$ & 0.5 & 31.6 & 24.5 & 17.6 & 16.5 & 16.2 & 16.2 & 16.2 & 16.1 & 16.1 & 16.1 \\
\hline$p_{2}^{L k}(9)$ & 0.5 & 9.2 & 13.6 & 9.1 & 8.4 & 8.3 & 8.2 & 8.2 & 8.2 & 8.2 & 8.2 \\
\hline$p_{2}^{L k}(10)$ & 0.5 & 0.8 & 2.9 & 1.8 & 1.6 & 1.6 & 1.6 & 1.6 & 1.6 & 1.6 & 1.6 \\
\hline$p_{2}^{L k}(11)$ & 0.5 & 0.0 & 0.2 & 0.1 & 0.1 & 0.1 & 0.1 & 0.1 & 0.1 & 0.1 & 0.1 \\
\hline$p_{2}^{L k}(12)$ & 0.5 & 0.0 & 0.0 & 0.0 & 0.0 & 0.0 & 0.0 & 0.0 & 0.0 & 0.0 & 0.0 \\
\hline$p_{2}^{L k}(13)$ & 0.5 & 0.0 & 0.0 & 0.0 & 0.0 & 0.0 & 0.0 & 0.0 & 0.0 & 0.0 & 0.0 \\
\hline$p_{2}^{L k}(14)$ & 0.5 & 0.0 & 0.0 & 0.0 & 0.0 & 0.0 & 0.0 & 0.0 & 0.0 & 0.0 & 0.0 \\
\hline$p_{2}^{L k}(15)$ & 0.5 & 0.0 & 0.0 & 0.0 & 0.0 & 0.0 & 0.0 & 0.0 & 0.0 & 0.0 & 0.0 \\
\hline
\end{tabular}

see that the $\mathrm{NN}$ fits the spike in quantity 10 in period 1 better than the $\mathrm{CH}$ model but the $\mathrm{CH}$ model fits the spike in quantity 8 in period 2 better than the NN model.

Table 7 displays, for the first five rounds of play and for $\tau$ equal to 1.29 , the probability that a player of level $k$ chooses an action from $\{3, \ldots, 15\} \cup\{W\}$ in period 2 and the probability he chooses an action from $\{3, \ldots, 15\}$ in period 2 . The table also displays, in the second row, the shares of level $k$ players for $k \in\{0,1,2, \ldots, 10\}$.

As we have seen in Sect. 3, an estimate for $\tau$ of 1.29 for the first five rounds of play implies that an "unperturbed" $L 1$ as well as an "unperturbed" $L 2$ commit to period 2. Table 7 show us that when $\tau$ is 1.29 a "perturbed" $L 1$ commits to period 1 with 
Table 8 Observed and predicted market outcomes

\begin{tabular}{|c|c|c|c|c|c|c|}
\hline \multirow[t]{2}{*}{ Market outcomes } & \multicolumn{3}{|c|}{ First 5 rounds } & \multicolumn{3}{|c|}{ Entire set } \\
\hline & Data & $\mathrm{CH}$ & NN & Data & $\mathrm{CH}$ & $\mathrm{NN}$ \\
\hline \multicolumn{7}{|l|}{ Cournot ( 8 or 9$)$ : } \\
\hline 1st period & 2.7 & 5.6 & 2.8 & 4.5 & 9.9 & 4.2 \\
\hline Sequential & 10.7 & 12.8 & 6.3 & 14.8 & 13.1 & 7.2 \\
\hline 2nd period & 6.7 & 7.4 & 3.5 & 4.5 & 4.5 & 3.0 \\
\hline \multicolumn{7}{|l|}{ Stackelberg: } \\
\hline Leader 12 , follower 6 & 4.0 & 0.7 & 1.6 & 0.9 & 0.4 & 1.5 \\
\hline Leader 11 or 10 , follower 7 & 9.4 & 3.4 & 7.7 & 6.5 & 2.9 & 6.8 \\
\hline \multicolumn{7}{|l|}{ First mover punished or rewarded: } \\
\hline Stackelberg leader punished & 6.7 & 2.4 & 0.9 & 11.9 & 2.4 & 0.8 \\
\hline Stackelberg leader rewarded & 0.0 & 1.8 & 0.1 & 0.2 & 1.8 & 0.1 \\
\hline Cournot ( 8 or 9 ) punished & 1.3 & 0.8 & 0.3 & 0.9 & 1.1 & 0.4 \\
\hline Cournot ( 8 or 9 ) rewarded & 0.0 & 6.4 & 0.2 & 0.0 & 7.5 & 0.3 \\
\hline Stackelberg and Cournot 1st period & 12.0 & 5.2 & 8.5 & 12.6 & 7.7 & 9.9 \\
\hline Double Stackelberg leadership & 10.7 & 1.2 & 6.4 & 6.3 & 1.5 & 5.8 \\
\hline \multicolumn{7}{|l|}{ Collusion: } \\
\hline Collusion successful & 4.0 & 3.7 & 0.9 & 6.1 & 4.1 & 0.9 \\
\hline Collusion failed & 5.3 & 6.9 & 7.5 & 10.6 & 11.0 & 7.7 \\
\hline Collusion exploited & 4.0 & 7.6 & 3.5 & 4.3 & 7.6 & 3.2 \\
\hline Other & 22.7 & 34.1 & 49.8 & 16.0 & 24.5 & 48.2 \\
\hline
\end{tabular}

probability $31.5 \%$, a "perturbed" $L 2$ commits to period 1 with probability $47.6 \%$, and both choose quantity 8 with the highest probability. The high percentage of $L 0 \mathrm{~s}$ and the fact that when a "perturbed" $L 1$ commits to period 1 he plays quantity 8 with a high probability imply that when a "perturbed" $L 2$ commits to period 1 he typically chooses a quantity less than 10 . This is the reason why the cognitive hierarchy model with quantal responses predicts spikes in quantities 8 and 9 in the first period and underestimates the first period spike in quantity 10 .

Table 8 compares the market outcomes predicted by the $\mathrm{CH}$ and $\mathrm{NN}$ models to those observed in the data for first five rounds of play and the entire set.

We see from Table 8 that both the $\mathrm{CH}$ and the NN models are able to generate heterogeneity in market outcomes. Both models also underestimate the percentage of: (i) Stackelberg outcomes where the leader produces 12 and the follower 6, and (ii) market outcomes where one player plays a Stackelberg quantity and the other a Cournot quantity in period 1 .

We also see from Table 8 that the $\mathrm{CH}$ fits four important features of market outcomes data better than the NN model. First, the percentage of Cournot outcomes predicted by $\mathrm{CH}$ model $(25.8 \%)$ is closer to the percentage in the data $(20.1 \%)$ than that predicted by the NN model (12.6\%). Second, the $\mathrm{CH}$ model predicts better simultaneous play of Cournot quantities in period 2 (delay). This is rather important since delay cannot be explained by risk-payoff equilibrium selection arguments or inequity aversion. Third, 
the $\mathrm{CH}$ model predicts better the percentage of leaders (Stackelberg or Cournot) who get punished by followers. Fourth, the percentage of market outcomes that fall under the category " other" predicted by $\mathrm{CH}$ model (34.1\%) is much closer to the percentage in the data $(22.7 \%)$ than that predicted by the NN model $(49.8 \%)$.

In contrast, the NN model fits four features of market outcomes data better than the $\mathrm{CH}$ model. First, the percentage of Stackelberg leader-follower outcomes predicted by the NN model $(9.3 \%)$ is closer to the percentage in the data $(13.4 \%)$ than that predicted by the $\mathrm{CH}$ model (4.1\%). Second, the $\mathrm{NN}$ model predicts better the percentage of leaders (Stackelberg or Cournot) who get rewarded by followers. Third, the NN model approximates better the percentages double Stackelberg leadership. Fourth, the percentage of collusive outcomes predicted by the NN model $(11.9 \%)$ is closer to the percentage in the data $(13.3 \%)$ than that predicted by the $\mathrm{CH}$ model $(18.2 \%)$.

Table 8 also shows that the predictions of market outcomes of the $\mathrm{CH}$ and the NN models in the first five rounds of play also extend to the entire set. The only difference being that the percentage of collusive outcomes predicted by the $\mathrm{CH}$ model $(22.7 \%)$ for the entire set is closer to the percentage in the data $(21.0 \%)$ than that predicted by the NN model (11.8\%).

\section{Conclusion}

This paper is an additional contribution to the literature on endogenous timing games. This literature shows that observed behavior in experiments on endogenous timing is at odds with the theory. The theory predicts Stackelberg outcomes but the experiments find that these are rare and, instead, Cournot outcomes are modal.

We apply the cognitive hierarchy model of Camerer et al. (2004) to Huck et al. (2002) discrete version of Hamilton and Slutsky (1990) action commitment game. We show that, for an empirically reasonable average level of thinking steps, the model rules out Stackelberg equilibria, generates Cournot outcomes including delay, and outcomes where the first mover produces more than Cournot but less than Stackelberg leader.

We also show that a cognitive hierarchy model with quantal responses can explain several of the most important features of the experimental evidence on the action commitment game in Huck et al. (2002). The model predicts spikes in the Cournot quantity in periods 1 and 2. The model's estimates for commitment to periods 1 and 2 are very similar to the data. In addition, the model generates heterogeneity in market outcomes, a high percentage of Cournot outcomes including simultaneous play of Cournot quantities in period 2 (delay), and a high percentage of outcomes where the first mover commits to a quantity higher than Cournot but lower than Stackelberg leader. Finally, we find that the model predicts collusive outcomes better in the entire set than in the first five rounds of play. It is out of the scope of this paper to study how a learning model can account for the dynamics in the data.

Acknowledgments We thank Vince Crawford, Joel Sobel, Miguel Costa-Gomes, and Nagore Irriberi for helpful comments and suggestions. We are also thankful to participants in the 24th Congress of the European Economic Association in Barcelona, and the 36th EARIE Conference in Ljubljana. 


\section{Appendix 1: Large payoff matrix}

see (Table 9)

Table 9 Large payoff matrix

\begin{tabular}{|l|c|c|c|c|c|c|c|c|c|c|c|c|c|}
\hline & 3 & 4 & 5 & 6 & 7 & 8 & 9 & 10 & 11 & 12 & 13 & 14 & 15 \\
\hline 3 & 54 & 51 & 48 & 45 & 42 & 39 & 36 & 33 & 30 & 27 & 24 & 21 & 18 \\
& 54 & 68 & 80 & 90 & 98 & 104 & 108 & 109 & 110 & 108 & 104 & 98 & 90 \\
\hline 4 & 68 & 64 & 60 & 56 & 52 & 48 & 44 & 40 & 36 & 32 & 28 & 24 & 19 \\
& 51 & 64 & 75 & 84 & 91 & 96 & 99 & 100 & 99 & 96 & 91 & 84 & 75 \\
\hline 5 & 80 & 75 & 70 & 65 & 60 & 55 & 50 & 45 & 40 & 35 & 29 & 25 & 20 \\
& 48 & 60 & 70 & 78 & 84 & 88 & 89 & 90 & 88 & 84 & 78 & 70 & 60 \\
\hline 6 & 90 & 84 & 78 & 72 & 66 & 60 & 54 & 48 & 41 & 36 & 30 & 24 & 18 \\
& 45 & 56 & 65 & 72 & 77 & 80 & 81 & 80 & 77 & 72 & 65 & 56 & 45 \\
\hline 7 & 98 & 91 & 84 & 77 & 70 & 63 & 55 & 49 & 42 & 35 & 28 & 21 & 14 \\
& 42 & 52 & 60 & 66 & 70 & 72 & 71 & 70 & 66 & 60 & 52 & 42 & 30 \\
\hline 8 & 104 & 96 & 88 & 80 & 72 & 64 & 56 & 48 & 40 & 32 & 24 & 16 & 8 \\
& 39 & 48 & 55 & 60 & 63 & 64 & 63 & 60 & 55 & 48 & 39 & 28 & 15 \\
\hline 9 & 108 & 99 & 89 & 81 & 71 & 63 & 54 & 45 & 36 & 27 & 18 & 9 & 0 \\
& 36 & 44 & 50 & 54 & 55 & 56 & 54 & 50 & 44 & 36 & 26 & 14 & 0 \\
\hline 10 & 109 & 100 & 90 & 80 & 70 & 60 & 50 & 40 & 30 & 20 & 10 & 0 & -10 \\
& 33 & 40 & 45 & 48 & 49 & 48 & 45 & 40 & 33 & 24 & 13 & 0 & -15 \\
\hline 11 & 110 & 99 & 88 & 77 & 66 & 55 & 44 & 33 & 22 & 11 & 0 & -11 & -22 \\
& 30 & 36 & 40 & 41 & 42 & 40 & 36 & 30 & 22 & 12 & 0 & -14 & -30 \\
\hline 12 & 108 & 96 & 84 & 72 & 60 & 48 & 36 & 24 & 12 & 0 & -12 & -24 & -36 \\
& 27 & 32 & 35 & 36 & 35 & 32 & 27 & 20 & 11 & 0 & -13 & -28 & -45 \\
\hline 13 & 104 & 91 & 78 & 65 & 52 & 39 & 26 & 13 & 0 & -13 & -26 & -39 & -52 \\
& 24 & 28 & 29 & 30 & 28 & 24 & 18 & 10 & 0 & -12 & -26 & -42 & -60 \\
\hline 14 & 98 & 84 & 70 & 56 & 42 & 28 & 14 & 0 & -14 & -28 & -42 & -56 & -70 \\
& 21 & 24 & 25 & 24 & 21 & 16 & 9 & 0 & -11 & -24 & -39 & -56 & -75 \\
\hline 15 & 90 & 75 & 60 & 45 & 30 & 15 & 0 & -15 & -30 & -45 & -60 & -75 & -90 \\
& 18 & 19 & 20 & 18 & 14 & 8 & 0 & -10 & -22 & -36 & -52 & -70 & -90 \\
\hline
\end{tabular}

\section{Appendix 2: Classification of market outcomes}

Table 10 provides the classification of market outcomes. Specifically, the table is composed of four different matrices. The upper left refers to cases where both players commit to period 1 , the lower right refers to cases where both players commit to period 2 , and the remaining two tables refer to sequential play. The notation employed is as follows:

Cournot outcomes:

$\mathrm{C}_{1}$ - Cournot 1 st period

$\mathrm{C}_{12}$-Sequential play of Cournot quantities

$\mathrm{C}_{2}-$ Cournot 2 nd period

Stackelberg outcomes: 
Table 10 Market outcomes classification

\begin{tabular}{|c|c|c|c|c|c|c|c|c|c|c|c|c|c|c|c|}
\hline & & \multicolumn{7}{|c|}{$t=1$} & \multicolumn{7}{|c|}{$t=2$} \\
\hline & & 6 & 7 & 8 & 9 & 10 & 11 & 12 & 6 & 7 & 8 & 9 & 10 & 11 & 12 \\
\hline \multirow[t]{7}{*}{$t=1$} & 6 & CS & CS & $\mathrm{CF}$ & $\mathrm{CF}$ & $\mathrm{CF}$ & $\mathrm{CF}$ & $\mathrm{CF}$ & CS & CS & $\mathrm{CE}$ & $\mathrm{CE}$ & $\mathrm{CE}$ & $\mathrm{CE}$ & $\mathrm{CE}$ \\
\hline & 7 & CS & CS & $\mathrm{CF}$ & $\mathrm{CF}$ & $\mathrm{CF}$ & $\mathrm{CF}$ & $\mathrm{CF}$ & CS & CS & $\mathrm{CE}$ & CE & $\mathrm{CE}$ & $\mathrm{CE}$ & $\mathrm{CE}$ \\
\hline & 8 & $\mathrm{CF}$ & $\mathrm{CF}$ & $\mathrm{C}_{1}$ & $\mathrm{C}_{1}$ & $\mathrm{SC}$ & $\mathrm{SC}$ & SC & $\mathrm{CR}$ & CR & $\mathrm{C}_{12}$ & $\mathrm{C}_{12}$ & $\mathrm{CP}$ & $\mathrm{CP}$ & $\mathrm{CP}$ \\
\hline & 9 & CF & CF & $\mathrm{C}_{1}$ & $\mathrm{C}_{1}$ & $\mathrm{SC}$ & $\mathrm{SC}$ & $\mathrm{SC}$ & CR & CR & $\mathrm{C}_{12}$ & $\mathrm{C}_{12}$ & $\mathrm{CP}$ & $\mathrm{CP}$ & $\mathrm{CP}$ \\
\hline & 10 & $\mathrm{CF}$ & $\mathrm{CF}$ & SC & SC & DL & DL & DL & SR & $\mathrm{S}_{10}$ & SP & SP & SP & SP & SP \\
\hline & 11 & $\mathrm{CF}$ & $\mathrm{CF}$ & $\mathrm{SC}$ & $\mathrm{SC}$ & DL & DL & DL & SR & $S_{11}$ & SP & SP & SP & SP & SP \\
\hline & 12 & $\mathrm{CF}$ & $\mathrm{CF}$ & $\mathrm{SC}$ & SC & DL & DL & DL & $\mathrm{S}_{12}$ & SP & SP & SP & SP & SP & SP \\
\hline \multirow[t]{7}{*}{$t=2$} & 6 & CS & CS & CR & CR & SR & SR & $S_{12}$ & CS & CS & $\mathrm{O}$ & $\mathrm{O}$ & $\mathrm{O}$ & $\mathrm{O}$ & $\mathrm{O}$ \\
\hline & 7 & CS & CS & $\mathrm{CR}$ & $\mathrm{CR}$ & $\mathrm{S}_{10}$ & $S_{11}$ & SP & CS & CS & $\mathrm{O}$ & $\mathrm{O}$ & $\mathrm{O}$ & $\mathrm{O}$ & $\mathrm{O}$ \\
\hline & 8 & $\mathrm{CE}$ & $\mathrm{CE}$ & $\mathrm{C}_{12}$ & $\mathrm{C}_{12}$ & SP & SP & SP & $\mathrm{O}$ & $\mathrm{O}$ & $\mathrm{C}_{2}$ & $\mathrm{C}_{2}$ & $\mathrm{O}$ & $\mathrm{O}$ & $\mathrm{O}$ \\
\hline & 9 & CE & CE & $\mathrm{C}_{12}$ & $\mathrm{C}_{12}$ & SP & SP & SP & $\mathrm{O}$ & $\mathrm{O}$ & $\mathrm{C}_{2}$ & $\mathrm{C}_{2}$ & $\mathrm{O}$ & $\mathrm{O}$ & $\mathrm{O}$ \\
\hline & 10 & $\mathrm{CE}$ & $\mathrm{CE}$ & $\mathrm{CP}$ & $\mathrm{CP}$ & SP & SP & SP & $\mathrm{O}$ & $\mathrm{O}$ & $\mathrm{O}$ & $\mathrm{O}$ & $\mathrm{O}$ & $\mathrm{O}$ & $\mathrm{O}$ \\
\hline & 11 & CE & CE & $\mathrm{CP}$ & $\mathrm{CP}$ & SP & SP & SP & $\mathrm{O}$ & $\mathrm{O}$ & $\mathrm{O}$ & $\mathrm{O}$ & $\mathrm{O}$ & $\mathrm{O}$ & $\mathrm{O}$ \\
\hline & 12 & $\mathrm{CE}$ & CE & $\mathrm{CP}$ & $\mathrm{CP}$ & SP & SP & SP & $\mathrm{O}$ & $\mathrm{O}$ & $\mathrm{O}$ & $\mathrm{O}$ & $\mathrm{O}$ & $\mathrm{O}$ & $\mathrm{O}$ \\
\hline
\end{tabular}

$\mathrm{S}_{12}$ - Stackelberg leader 12, follower 6

$\mathrm{S}_{11}$-Stackelberg leader 11, follower 7

$\mathrm{S}_{10}$ - Stackelberg leader 10, follower 7

First mover punished or rewarded:

SP_Stackelberg leader punished

SR_-Stackelberg leader rewarded

$\mathrm{CP}$-Cournot punished

CR-Cournot rewarded

SC-Stackelberg and Cournot in 1st period

DL_-Double Stackelberg leadership

Collusive outcomes:

CS-Collusion successful

$\mathrm{CF}-$ Collusion failed

CE-Collusion exploited

$\mathrm{O}$-Other market outcomes.

\section{References}

Camerer C, Ho T, Chong J (2004) A cognitive hierarchy model of games. Q J Econ 119(3):861-898

Costa-Gomes M, Crawford V (2006) Cognition and behavior in two person guessing games: an experimental study. Am Econ Rev 96:1737-1768

Costa-Gomes M, Crawford V, Broseta B (2003) Experimental studies of strategic sophistication and cognition in normal-form games. Econometrica 69:1193-1235

Crawford V, Iriberri N (2007) Fatal attraction: salience, naiveté, and sophistication in "hide-and-seek" games. Am Econ Rev 97(5):1731-1750 
Crawford V, Costa-Gomes M, Iriberri N (2013) Structural models of nonequilibrium strategic thinking: theory, evidence, and applications. J Econ Lit 51:5-62

El-Gamal M, Grether D (1995) Are people Bayesian: uncovering behavioral strategies. J Am Stat Assoc 97(432):1137-1145

Fonseca M, Müller W, Normann H-T (2006) Endogenous timing in duopoly: experimental evidence. Int J Game Theory 34:443-456

Hamilton J, Slutsky S (1990) Endogenous timing in duopoly games: Stackelberg or Cournot equilibria. Games Econ Behav 2:29-46

Harless D, Camerer C (1995) An error rate analysis of experimental data testing Nash refinements. Eur Econ Rev 39:649-660

Harsanyi J, Selten R (1988) A general theory of equilibrium selection in games. MIT Press, Cambridge

Huck S, Müller W, Normann H-T (2001) Stackelberg beats Cournot—on collusion and efficiency in experimental markets. Econ J 111:749-765

Huck S, Müller W, Normann H-T (2002) To commit or not to commit: endogenous timing in experimental duopoly markets. Games Econ Behav 38:240-264

Ivanov A, Levin D, Peck J (2009) Hindsight, foresight and insight: an experimental study of a small-market investment game with common and private values. Am Econ Rev 99(4):1484-1507

Matsumura T (2001) Market instability in a Stackelberg duopoly. J Econ 75(3):199-210

McKelvey R, Palfrey T (1995) Quantal response equilibria in normal form games. Games Econ Behav 10:6-38

McKelvey R, Palfrey T (1998) Quantal response equilibria for extensive form games. Exp Econ 1:9-41

Nagel R (1995) Unraveling in guessing games: an experimental study. Am Econ Rev 85(5):1313-1326

Östling R, Wang J, Chou E, Camerer C (2011) Testing game theory in the field: Swedish LUPI lottery games. Am Econ J Microecon 3:1-33

Robson A (1990) Duopoly with endogenous strategic timing: Stackelberg regained. Int Econ Rev 31(2):263274

Rogers B, Palfrey T, Camerer C (2009) Heterogeneous quantal response equilibrium and cognitive hierarchies. J Econ Theory 144:1440-1467

Saloner G (1987) Cournot duopoly with two production periods. J Econ Theory 42:183-187

Santos-Pinto L (2008) Making sense of the experimental evidence on endogenous timing in duopoly markets. J Econ Behav Organ 68:657-666

Schwarz G (1978) Estimating the dimension of a model. Ann Stat 6(2):461-464

Stahl D, Wilson P (1994) On player's models of other players: theory and experimental evidence. Games Econ Behav 10:218-254 